\title{
La moda en Santa Cruz de Tenerife bajo el reinado de Isabel II (1833-1868)
}

\author{
Fashion in Santa Cruz de Tenerife During the Reign of Isabella II \\ (1833-1868)
}

\author{
Carlos Javier Castro Brunetto \\ Universidad de La Laguna \\ http:/ / orcid.org/0000-0002-1007-8309 \\ cbrunett@ull.edu.es
}

Recibido: 26/06/2020; Revisado: 30/07/2020; Aceptado: 22/10/2020

\begin{abstract}
Resumen
La moda es un campo de las artes visuales que ha sido muy poco estudiado en Canarias en general y en Santa Cruz de Tenerife en particular. Nuestra investigación pretende contribuir en ese espacio del conocimiento realizando un estudio sobre la moda durante el reinado de Isabel II (1833-1868) en la que fuese la primera capital de la provincia de Canarias. Para ello hemos empleado como fuente la prensa escrita, en la que distinguimos entre los textos que plantean la importancia ética, social y cultural de la moda, sea a favor o en contra, y los que abordan las novedades del momento provenientes de París y conocidas en Tenerife gracias a los periódicos de Madrid.
\end{abstract}

Palabras clave: Arte, moda, prensa, siglo XIX, Santa Cruz de Tenerife.

\begin{abstract}
Fashion is a field of the visual arts that has scarcely been studied in the Canary Islands in general, and in Santa Cruz de Tenerife in particular. Our research aims to contribute to this ambit of knowledge by conducting a study of fashion during the reign of Isabella II of Spain (1833-1868), when Santa Cruz was the first capital of the province of the Canary Islands. With the written press as this article's main source, we distinguish between texts that raise the ethical, social and cultural importance of fashion, whether for or against, and those that address the latest novelties from Paris, arriving in Tenerife through the newspapers of Madrid.
\end{abstract}

Key words: Art, Fashion, Press, Nineteenth Century, Santa Cruz de Tenerife. 


\section{INTRODUCCIÓN. EL ESPACIO DE LA MODA}

En 1833 se producirán dos fastos significativos para la historia de Canarias; el primero de carácter nacional, el ascenso al trono (en periodo de regencia) de la reina Isabel II (1830-1904) en función de la derogación de la ley sálica, y el segundo, la designación de Santa Cruz de Tenerife como capital de la provincia de Canarias, tras la división territorial de España de noviembre de ese año. El auge de la ciudad burguesa, comercial e internacional se vio impulsado por el santacrucero José Murphy y Meade (1774-1841), determinante para el nombramiento de la ciudad tinerfeña como candidata a capital provincial y artífice crucial de la futura Ley de Puertos Francos aprobada en 1852, que tantas ventajas aportaría al desarrollo del comercio canario hasta la actualidad.

La innegable inyección de autoestima ya había sido anunciada en 1803 cuando Carlos IV firmaba el título de villa exenta, con privilegios jurisdiccionales y quedó rematada en 1866 al recibir del gobierno el título de ciudad. Evidencia del nuevo impulso económico, social y cultural de Santa Cruz lo encontramos en el asociacionismo, que cobra un gran auge desde 1840, cuando se funda el Gabinete de Lectura y de Recreo que pocos años después se transformará en la sociedad que llega a la actualidad con el nombre de Real Casino de Tenerife. En 1855 se crea la sociedad patriótica y popular El Recreo y poco después la sociedad El Progreso, que cambió por el nombre de La Aurora. Ambas tenían un origen esencialmente popular, conformada por artesanos y otros profesionales, acabaron fusionándose con la sociedad XII de Enero hasta crear en 1903 el actual Círculo de Amistad XII de Enero (Cioranescu, 1979, v. Iv: 142-144). Por otro lado, la real cédula en 1835 constituyó la Escuela Náutica, y por Real Decreto de 31 de octubre de 1849, la Academia Provincial de Bellas Artes [de Canarias] con sede en la ciudad, que tras un letargo en los años finales del siglo XIX, fue reactivada por Alfonso XIII en 1913, como Real Academia Canaria de Bellas Artes de San Miguel Arcángel, institución que recogía la experiencia docente en el campo de las bellas artes iniciado en Santa Cruz desde el siglo xvIII (Figura 1).

Estas asociaciones, ya fuesen con finalidad cultural o recreativa, tenían entre sus miembros a personas de una extracción social mayoritariamente burguesa, interesada en la actividad comercial. También se sumaron personas de un origen socioeconómico inferior para los criterios de la época, lo que señala un temperamento nuevo alejado de los valores tradicionales y la estratificación asociada al Antiguo Régimen. No obstante, la realidad canaria sufrió los efectos de la devastadora desamortización del ministro Mendizábal para el patrimonio artístico, la primera guerra carlista bajo la regencia de María Cristina, la regencia del general Espartero y el inicio del gobierno personal de la propia reina Isabel hasta llegar a la revolución de 1868 que destronó a la monarca. Fueron años inestables, aunque para Canarias supuso el despegue definitivo de su exportación de cochinilla y la importación de productos de lujo que, por primera vez en la historia, llegaban a nuevas capas de la sociedad con capacidad para valorar y consumir los efectos de una industria que poco a poco iba imponiéndose: la moda.

El espectro fenomenológico de la moda encubre bajo una supuesta opción 
personal -la elección de las prendas-, una realidad de consumo de masas dirigida por la industria y el comercio textil, que envuelve sutilmente a la burguesía y a nuevas clases aupadas perspicazmente hacia ese mundo, gracias a la publicidad que crece bajo el contexto de la revolución industrial.

El filósofo alemán y uno de los padres de la sociología, Georg Simmel (18581918), redactó un ensayo publicado en 1905 bajo el título Filosofía de la Moda en el que mostraba su perplejidad por la contradicción entre el ansia de mejorar, de sufrir una transformación regeneradora a través del disfrute de la moda y cómo en el momento de alcanzarla, la propia idea de moda muere, para resurgir con otro aspecto:

Trae consigo la esencia de la moda que solo participe de ella una parte de la sociedad, mientras el resto de halla siempre camino de ella, sin alcanzarla nunca. Tan pronto como se ha extendido por todos lados, es decir, tan pronto como lo que al principio solo algunos hacían sea empleado por todos, como acaece con ciertos elementos del traje y el trato social, pierde su condición de moda (SIMMEL, 2014: 46-47).

Este ensayo de SIMMEL, estudiado por Jorge LozANo, propone el gran debate sobre la moda durante el siglo XIX. Es decir, que el disfrute de las innovaciones en el vestir o en el adorno, que hasta entonces había sido un privilegio de las cortes y las élites asociadas, llega hasta unos niveles sociales inusitados cien años antes. La Revolución Francesa y el periodo napoleónico democratizó el vestir con lujo; pero toda vez que una moda alcanzaba su auge, pronto moría, porque la vulgarización de una idea genial comenzaba a ser inaceptable para sus primeros seguidores, que ansiaban nuevas formas.

Así pues, la moda en el Ochocientos nace buscando la originalidad, se desarrolla en la expectativa del éxito social que presupone la consumación del deseo y muere en el mismo momento en que se disfruta, transformándose en algo vulgar. Se torna evidente el hecho de que la propia idea de moda está coligada al negocio, a la industria y a la inmediatez del consumo, enfrentándose a los valores de la tradición, la moral y el espíritu conservador (Figura 2).

Esta idea nos conduce a otra: que la moda se instaura como un elemento iconográfico de representación individual, aunque, contrariamente, nace para divulgarse colectivamente. $Y$ decimos que es una pieza iconográfica en el sentido de que describe una personalidad que desea ser original y exitosa, aunque sea por imitación, a través de ese discurso visual. Pero solo busca transmitir una imagen, no necesariamente (casi nunca) una filosofía o visión de vida. Jorge Lozano (2000) sostiene que «el carácter abstracto y arbitrario de la moda se manifiesta en la indiferencia de la moda, en tanto que forma, frente a sus contenidos». Por tanto, moda y arbitrariedad, desde el siglo XIX, van del mano, pero también moda, éxito social y discurso iconográfico.

Como es natural, este punto de partida pone en evidencia, conforme avanza el siglo XIX, la sima que separa la búsqueda de la originalidad en el vestir y el factor moda, es decir, la mutación de lo sublime en lo ordinario. Será en París donde alcance el culmen el couturière diseñando la haute-couture, construida desde la silueta y el detalle y obsesionada por crear una obra de arte en movimiento 
erigida con textiles. En paralelo, otros couturières que cosen para rentas más bajas, con medios inferiores, aunque con mucho esfuerzo, crean tendencias inspiradas por esas obras maestras para que los paseos por los Campos Elíseos un bonito domingo recuerden vagamente las veladas en la Ópera de París y el hipódromo de Longchamp. Sin quererlo, coser para la élite estructuraba uno de los primeros grandes negocios realmente democráticos, la moda, que acabará viajando desde la Rue de la Paix en el siglo XIX hasta el emporio Zara del siglo XXI (VELASCO, 2019: 53-68).

Asimismo, otro aspecto que ya se aprecia durante el siglo xIX y que contemplaremos en el caso de Santa Cruz, es que las implicaciones sociales de la moda exigen que las personas verdaderamente elegantes (como se manifiesta en la prensa de la época), consideren que todo adorno e innovación es poco si se desea estar a la moda. De tal manera que lo barato, lo que puede llegar a cualquier consumidor, acaba desapareciendo de la visión de la auténtica moda. En un ensayo sobre el valor pecuniario de la moda, Thorstein VEBLEN (2015: 56-57) apunta lo siguiente:

En materia de vestido se siente la verdad de la expresión «barato y malo» aun con
menos atenuaciones que en otras direcciones del consumo. Sobre la base del gusto
y la utilidad, un artículo de vestir que no sea costoso se considera como inferior
con arreglo a la máxima «barato y malo». Hasta cierto punto, encontramos que las
cosas son bellas -y útiles- en proporción a su costo. Con pocas y no importantes
excepciones, todos encontramos que -tanto por lo que se refiere a la belleza como en
lo relativo a la utilidad- es preferible un artículo de vestido costoso y hecho a mano
a una imitación menos costosa de él.

Como veremos, todas estas premisas acontecen en la moda de Santa Cruz de Tenerife bajo el periodo isabelino. El progresivo enriquecimiento de la burguesía, la accesibilidad al comercio gracias a la apertura de tiendas que venden tejidos y moda confeccionada, la creciente posibilidad de llevar a casa variados objetos de mercería y aderezos para sombreros y tocados que permiten crear una «iconografía» personal, que luego se irá conociendo como estilo, asume el principio esencial de la moda: forjar un diseño, expandirlo rápidamente bajo el criterio de la accesibilidad y morir de manera fulminante tan pronto alcanza éxito otro diseño. Pero también existe un nuevo concepto asociado a la moda: el nacionalismo. En este caso no en la vertiente que podemos asociar en la actualidad, de la indumentaria tradicional a la moda, sino en el decimonónico, es decir, la exaltación de la gran patria española. ¿Y cómo entronca este concepto con la moda, Francia y Tenerife? En un artículo de opinión insertado en la sección variedades de El Noticioso de Canarias en 1853, se exalta a la emperatriz de los franceses, Eugenia de Montijo, como referencia de mujer, de española, de emperatriz y de icono de la moda:

(...) ¿Qué nombre pasa hoy en París como una conmoción eléctrica por todos los salones? Ya estoy oyendo contestar ¡Eugenia! (...) Para mí la Emperatriz es una compatriota hermosa y elegante y de un gusto más que artístico, fabuloso. Nadie como ella sabe llevar la gasa, la seda y los tocados. Por ello he visitado ante todo sus 
proveedores privilegiados $(\ldots)^{1}$

En definitiva, que la figura de la monarca francesa nacida española se convirtió en una referencia de estilo que forjaría una iconografía a la que aspiraban todas las burguesas del país, incluidas las lectoras tinerfeñas que, henchidas de nacionalismo patrio, leían con devoción todo lo relacionado con la emperatriz y sus vestidos; ataviarse con la disposición de Eugenia era vestir a la moda. Relacionado con lo anterior y como un fenómeno intrínseco de la moda, es el aumento de oportunidades para lucirla, pues de nada vale un nutrido armario sin la ocasión de exhibirlo. De hecho, el mayor enemigo de la moda no es cualquier crisis económica, sino el tedio. En este sentido, en 1847 el ayuntamiento de Santa Cruz decide levantar un teatro para suplir las necesidades de actividad cultural de la ciudad. El arquitecto municipal Manuel de Oraá y Arcocha (1822-1889) en 1848 firma el proyecto y se estará trabajando en él, con algunas modificaciones, hasta 1851 (FragA, 1999: 67-75). Pocos años después, los espacios urbanos dedicados al paseo, $y$, en consecuencia, escenario natural de la moda, serían modificados en la trama urbana. La entretenida lectura de las crónicas de Francisco Martínez Viera sobre Santa Cruz en la segunda mitad del Ochocientos, publicadas en la década de 1950, relatan la construcción de la Plaza del Príncipe entre 1857 y 1860, proyecto del arquitecto Manuel de Oraá (MARTínez, 2003: 107-108), la ampliación entre 1860-1861 de la plaza de la Constitución (actual Plaza de la Candelaria) restando terreno al desaparecido castillo de San Cristóbal y de la que se derivó una alameda que conectase con la alameda de La Marina, que recibiría el nombre de rambla de Ravenet (MARTíneZ, 2003, pp. 84-85).

En cuanto a las fuentes empleadas para la argumentación de este trabajo, el género de retrato pictórico podría ser una pista en el camino investigador. ${ }^{2}$ De hecho, para conocer la historia de la indumentaria y de la moda hasta el reinado de Isabel II, era prácticamente imposible trabajar sin él, y ya hemos experimentado su uso para comprender el fenómeno de la moda en Canarias bajo la influencia de Francia a lo largo del siglo XVIII. ${ }^{3}$ La documentación procedente en otras fuentes archivísticas, como mucho, informa de la existencia de indumentos, tejidos o complementos, pero es arriesgado presuponer un conocimiento exhaustivo del escribano o redactor del documento sobre los atuendos para que ofrezca absoluta fiabilidad. Por otro lado, la elección de los atavíos a combinar para inspirar un retrato no necesariamente habla de moda, sino de una elección determinada que busca la inmortalidad que entraña la ejecución del cuadro.

Por ello, el género del retrato es una fuente, sí, pero secundaria. Tampoco lo será la fotografía; es tentador considerar que la llegada del retrato fotográfico, las carte de visite o retratos para regalar a familiares y amigos, recogiese el espíritu de la moda, pero debido al periodo que estudiamos, la fotografía sólo aparece al final de nuestro estudio con el asentamiento en Santa Cruz del fotógrafo Santos

1 Sin firma. «Variedades», El Noticioso de Canarias: 11 de mayo de 1853, Santa Cruz de Tenerife: 2-3.

2 Para el caso del romanticismo canario, una visión transversal de gran interés es la ofrecida por Jonathan ALLEN (2002: 108-119).

3 Hemos desarrollado una metodología para el estudio de la moda en el arte canario del siglo XVIII partiendo del género del retrato (CASTRO, 2017: 1-22) 
María Pego en la década de 1860, eso sí, con la sustitución del daguerrotipo por el papel. De hecho, la mayoría de las fotos más antiguas conservadas apuntan a años más tarde. Entre los primeros fotógrafos hemos de reseñar junto a Pego, a Rafael Belza o Manuel García Rodríguez, y en Gran Canaria a Luis Ojeda Pérez, además de extranjeros estantes en Tenerife. A ellos se sumará en décadas siguientes el pintor y fotógrafo tinerfeño Marcos Baeza (1858-1915), iniciado en este campo desde la década de 1880 (VeGA, 1992: 56-71). Para estudiar estos retratos, aunque de cronología incierta, es muy útil consultar el archivo del FEDAC del Cabildo de Gran Canaria, ${ }^{4}$ que muestra fotografías tomadas en su mayoría de 1865 en adelante, siendo ya comunes en la década de 1880 (Figura 3).

Así pues, la fuente más fiable es la prensa. Afortunadamente, el siglo XIX se inicia con la irrupción de la prensa escrita en la capital tinerfeña desde que en 1808 se lanza El Correo de Tenerife. Pero el verdadero interés de los rotativos cobra fuerza con la creación provincial con capitalidad en la ciudad y el establecimiento del Boletín oficial de Canarias, que ya incluye una sección de anuncios, siendo algunos, reclamos de moda. ${ }^{5}$ Será en la década de 1850 cuando se experimente un verdadero crecimiento de la prensa publicada con regularidad, no solo semanarios, sino tres o cuatro números por semana. En las secciones del mismo, la moda aparece en varios apartados. A veces se trata de una reflexión editorial; en otras ocasiones, en la sección variedades se toma de otro periódico de tirada nacional (habitualmente prensa madrileña, que era la que se recibía por medio de los vapores llegados al puerto), un artículo de opinión sobre el concepto de la moda, asociado comúnmente a lo banal o pasajero, con algún contenido moralista. También se copian recortes de prensa de moda que señalan las «modas» de París o de Madrid. Por último, en la sección de anuncios o publicidad, se informaba del género que se vendía en Santa Cruz. Este último apartado es, quizás, el que más nos interesa, pues revela las novedades que realmente llegaron a Santa Cruz en los años centrales del siglo y vistieron nuestros antepasados.

Entre los publicados entre 1833 y 1868, en función de la presencia de este factor entre sus páginas, el periódico que más y mejor reflejó el impacto de la moda bajo los epígrafes que hemos comentado fue El Eco del Comercio publicado entre 1852 y 1869. En menor medida, registran algunas referencias a la moda y se publican anuncios en El Eco de la juventud: correo semanal literario, artístico, religioso e industrial (1847-1848), La Fe: periódico de anuncios, literatura e intereses materiales (1857), El Fénix: periódico semanal de literatura, artes, comercio y mejoras materiales (1857 - 1865), El Guanche: periódico literario, científico, industrial, comercial y de intereses materiales (1858-1869) y El Mensajero de Canarias: periódico de anuncios comerciales, agrícolas e industriales (1865-1868). Otros periódicos también lo harán, pero de forma esporádica.

Por eso mismo, estamos en condiciones de asegurar que otros periódicos que han despertado el interés de los estudiosos de la cultura recogida en la prensa

4 Lo citamos de forma expresa por el valor y organización de los registros documentales fotográficos a disposición pública: https:// fedac.org/fotos-antiguas [Consulta: 30/07/2020].

5 Consideramos que la obra general de referencia para los estudios generalistas sobre la prensa en Canarias continúa siendo el texto de Ricardo AcIRón (1986). 
de la época, caso de La Aurora: semanario de literatura y de artes (1847-1848), no dedicaron especial interés por el vestir. En el mismo sentido, llama la atención que El Instructor y el Correo de las Damas, publicado en Santa Cruz entre noviembre de 1857 y agosto de 1858, nacido como un periódico con formato de revista femenina con artículos sobre las tendencias en la moda y como espacio dedicado a la «cultura femenina» (literatura, costura, cocina, etc...) acabase teniendo una incidencia muy escasa en nuestro ámbito. Para Ana María Velasco (2016: 320), estudiosa del tema en la prensa española del siglo XIX, al valorar este rotativo tinerfeño en su conjunto y en comparación con el resto de los títulos aparecidos en el resto del país, señala que «dará un modelo editorial muy particular, que es criticado por algunos por su insoportable frivolidad o por lo artificioso de su destino que no deja de ser el mantenimiento de la mujer dependiente del hombre y de la presión social». Lo que interesa a El Instructor, bajo la dirección y edición de Juan N. Romero, a su vez director del periódico El Guanche y propietario de la Imprenta Isleña, no es apoyar al mundo de la moda como cultura femenina, sino vender tiradas de forma expresa a ese público bajo el anzuelo de la moda. Por ello, debemos seguir señalando como la principal fuente de información a El Eco del Comercio por recoger el interés pecuniario de la moda en la trama de la economía burguesa de la ciudad y de la isla.

Dedicaremos los siguientes apartados a estudiar el concepto de moda y los hábitos de compra en la capital tinerfeña en los años centrales del siglo, a la luz de la prensa (Figura 4).

\section{ESTÉTICA DE LA MODA. ESTADOS DE OPINIÓN SOBRE LA MODA EN LA PRENSA TINERFEÑA}

La estética aplicada a la moda, disciplina que analiza la percepción de la belleza por los individuos y la sociedad, no fue como tal un objetivo de los periodistas locales, que sí recogían en los editoriales el estado de opinión, muchas veces controvertido, haciéndose eco de rotativos madrileños. Los más interesantes no abordaban la forma de vestir o adornarse, sino la ética de seguir o no los dictados de la moda. Este factor es crucial; aunque los ensayistas fuesen foráneos, los lectores asimilaban sus textos en el contexto social y cultural de Canarias y, por lo tanto, tenían la capacidad de influir sobre la masa crítica de la sociedad local.

En la prensa de los años cuarenta e inicios de los cincuenta, se escribía sobre la moda como algo pernicioso, contrario a los valores eternos. Pero en el mismo día y periódico era común la publicación de una materia que aconsejaba seguir la moda, o bien contenía anuncios que la promocionaban. Esto lo único que indica es que a pesar de la línea de pensamiento que definía al propio periódico (conservador, católico, liberal o comercial, si bien la mayoría era de tendencia liberal), al recalar en la moda se privilegiaba su función social y comercial. Además, se consideraba 
una materia idónea para el «bello sexo», ${ }^{6}$ que todo lo disculpaba.

La primera referencia sobre un aspecto concreto ligado a la moda que hemos registrado aparece en El Atlante en julio de 1838, donde se afirma que es contraria al buen juicio y antítesis de las condiciones que debe presidir la inteligencia, identificando la insensatez a la manera de sentir romántica:

(...) Si hasta los chiquitines, recién salidos del cascarón, son románticos. Ellos apenas sabrán deletrear el libro catón pero ¡como para ser romántico no es preciso nada!... ¡Precioso privilegio! He aquí la igualdad del género humano...Hombres ¿a qué divagáis buscando la sagrada igualdad primitiva? Sed románticos como en Santa Cruz y todos seréis iguales... ¡Si es mucho! Vas lector, al café y un joven á la dernière, con dos grandes rizos que cubren sus patilladas mejillas, flaco ¿es usted romántico? te pregunta... y añade ¡Oh! Yo lo soy...y furiosamente ¿No lo ve Vd.? Es moda... $(\ldots) .^{7}$

Es curiosa esta identificación de la exaltación romántica con la subversión del orden. En la misma línea ideológica se sitúa el autor anónimo del artículo que ahora proponemos, publicado 1839 que acusa a las élites de promover la ociosa y perniciosa moda en oposición a la sencillez y sinceridad de la vida rural, aunque admite finalmente que la moda forma parte de la sociedad:

(...) Si siempre ha gustado al hombre la variedad, si en todos tiempos se han sucedido unos a otros, y lo que hoy estaba en boga y parecía lo mejor y más bello, mañana se repetirá como ridículo y despreciable, en el presente siglo ha llegado la variedad al infinito, se suceden las modas con una claridad prodigiosa y se hacen extensivas a objetos que antes (a lo menos en muchos) no habían sufrido ninguno de estos frecuentes cambios. Un cargo se desprende a la generación presente y no sabemos cómo acertarán algunos a conciliar esta asombrosa veleidad e inclinación o gusto a las cosas frívolas y pasajeras, con ese positivismo que suponen en el siglo actual y de que hacen ostentación y gala. (...)

Son varios los escritores que propalan esa imagen nociva de la moda por medio de artículos de opinión publicados a lo largo de los años cincuenta, cada vez en menor número frente al aumento inverso de materias que difunden los gustos cotidianos del buen vestir bajo una innegable aureola comercial. El sentido moralista contrario a la moda lo observamos en un artículo de 1866, firmado por iniciales, en el que se apunta a la moda como origen de la decadencia y el derroche:

(...) Hoy se vive al día ¿quién piensa en el mañana? ¡Es tan corta la vida que no debemos tomarnos la molestia! Vístase a la moda. Un vestido a la moda un día, lo más a un mes. Aparezcamos hoy como princesas, mañana Dios dirá ¿Ganan las costumbres? La mujer, la hija, la hermana del artesano, del pequeño propietario, del empleado, del militar, aspiran a presentarse como la del capitalista, como la del rico hacendado, como la del magnate. La moda se lo permite, lo exige. Obrando de otro

6 Terminología de la época.

7 P.C. «Los románticos y antirrománticos», El Atlante, 1 de julio de 1838: Santa Cruz de Tenerife: 3. (En sección: opinión). 
modo aparecen desairadas." $(\ldots))^{8}$

Más descarnado es el ensayo firmado por N. en la línea editorial de El Eco del Comercio, en 1868, en vísperas de la caída de la reina, tal vez tomado de la prensa de Madrid, en el que se presenta el combate entre la moda (lujo) y la sencillez (virtud), es decir, el eterno combate entre el bien y el mal. Pero el mismo periódico que lo publica como editorial, acoge toda la publicidad posible en torno al comercio de la moda. El texto es el siguiente:

Uno de los males que aflige a la sociedad y penetra en todas sus clases, es el excesivo lujo, efecto de una desmesurada vanidad en unos, de pura imitación arrastrados por la costumbre o la moda, en otros, y de errada elección en los más, tomando ejemplo de donde únicamente deberían tomar escarmiento. Pero la vanidad es siempre la principal responsable de este mal social, que tanta miseria ha causado y ha de causar, relajando las costumbres, arruinando muchas familias y dando origen a los males consiguientes que afligen a la sociedad. (...). ${ }^{9}$ (Figura 5)

Hemos registrado un segundo grupo de artículos, no tan numeroso, cuya presencia es creciente conforme avanzan los años centrales del siglo, que considera la industria de la moda como una de las más florecientes del siglo. En la comercial ciudad de Santa Cruz de Tenerife, empieza a percibirse este fenómeno económico de forma favorable y la prensa copia opiniones tomadas de los periódicos de Madrid que defienden su auge nacional.

El Eco de la juventud: correo semanal literario, artístico, religioso e industrial, rotativo de corta vida entre $1847 / 1848$ destinado al fomento mercantil en un entorno burgués, toma nota de la siguiente información que plantea la necesidad del libre comercio, justificando que lo que un país no produce debe importarlo y si hay excesivos aranceles o prohibiciones se detiene la producción nacional, repercutiendo en todos los sectores. El ejemplo lo pone en la fabricación de la moda:

(...) La prosperidad comercial está indudablemente fundada en la exactitud de sus cálculos y la pronta circulación de sus efectos, quedando actividad a su capital, acelera las transacciones; para esto tiene que tomar por base el gusto y necesidades del consumidor, y este es el medio por que la moda, las necesidades y la baratura haciendo precisos muchos artículos, ponen al comerciante en la necesidad de proveerse de determinados efectos para cubrir las imperiosas necesidades del lujo y del vestido, necesidades que la mayor parte de las veces son del momento: si alguno de estos artículos se halla prohibido, vendrá a resultar que no pueden atenderse a las exigencias de los consumidores, y como el surtido es una de las principales garantías tendrá por consecuencia la paralización de sus negocios, y con ellos la ruina, o que hace su introducción fraudulenta bajo la esperanza de un seguro y abundante lucro $(\ldots) \cdot{ }^{10}$

8 P. de L. El Lujo, El Eco del Comercio, 11 de julio de 1866, Santa Cruz de Tenerife: 1.

9 «El lujo, la vanidad y la disipación», El Eco del Comercio, 2 de septiembre de 1868, Santa Cruz de Tenerife:1.

10 Sin firma, El Eco de la juventud: correo semanal literario, artístico, religioso e industrial, 15 de mayo 
En el mismo sentido, El Noticioso de Canarias de 1852, recoge un interesante artículo sobre los datos estadísticos del floreciente comercio de la moda en la villa de París; no es una opinión que revele cuestiones estéticas o novedades en la indumentaria, sino una relación de datos y cifras, probablemente con la idea de estimular la actividad comercial de ese sector.

París encierra en sus muros 879 tiendas y almacenes de modistas, de los cuales 867 están dirigidos por mujeres. Trabajan en estos establecimientos 2.717 oficialas, y venden al año por 13 millones de francos. Entran en esta clase de negocios los gorros, los sombreros, los adornos de la cabeza y otros renglones de fantasía (...) El término medio del jornal de las oficiales de modista es un franco y 98 centésimos; algunas de estas operarias viven en los establecimientos y gozan de un sueldo anual. Casi todas ellas son mujeres de buena conducta, y de ciento, noventa y ocho saben leer y escribir, proporción que no se encuentra en ningún otro oficio (...). ${ }^{11}$

El último grupo que podemos destacar son los artículos que se consagran a las modas en el vestir, tomados de la prensa madrileña que plasman la parisina. En la mayor parte de los casos se declaraba la fuente, normalmente las revistas madrileñas llegadas a Santa Cruz en los últimos vapores arribados desde Cádiz o Alicante. Suelen ser comentarios anónimos, pero también hay algunos firmados por escritoras como Ángela Grassi, y desde mediados de la década de 1850, Aurora Pérez Mirón, seudónimo de la escritora Joaquina García Balmaseda (THION, 2011: 396), ambas ligadas íntimamente a la publicación madrileña El Correo de la Moda, entre 1851 y 1893 (VELASCO: 2016: 299).

Mención especial merece la figura de Carmela, que firma varios artículos para El Eco del Comercio entre las primaveras de 1863 y 1864. En principio, podría parecer que se trata de una copia más de la prensa madrileña, pero en función de la redacción, se percibe que es alguien que escribe desde Santa Cruz y para Santa Cruz. En todos sus artículos destaca de manera un tanto forzada el clima de intimidad con las lectoras y nunca añade apellido. Tras comparar la forma de redactar con otros textos de modas, creemos que se trata de un seudónimo (algo muy común en la época) empleado por algún redactor de El Eco, con el fin de resultar más amigable y fomentar la complicidad del público femenino y, con ese ardid, mejorar las ventas. Es muy posible que Carmela fuese el resultado de reproducir otros artículos de moda, tal vez de números ligeramente atrasados de El Correo de la Moda y modificados con anécdotas locales para crear ese ambiente de cercanía. En algún caso puntual, sí parece relatar un acontecimiento social, como un día de paseo y un baile en el Casino de Tenerife ocurrido en 1863, donde parece conjugar el contenido de moda y la crónica social:

(...) De aquí la transformación que ya está experimentando nuestra toilette. Tenemos que abandonar las tartalanas y los barés y todas esas ligeras gasas que con tanto gusto veíamos ondular en nuestra plaza y alameda, al soplo agradable de nuestra

de 1848, Santa Cruz de Tenerife: 2.

11 Estadística de la moda, El Noticioso de Canarias, 13 de marzo de 1852, Santa Cruz de Tenerife: 3. 
agradable brisa marina. El tafetán o alpaca, las telas de abrigo en fin, ocuparán ahora el puesto de las gasas, y a propósito de estas telas, he visto algunos vestidos muy lindos en el paseo del lunes que estuvo bastante animado, dándole una grata variedad los diferentes uniformes de nuestros marinos y de los oficiales franceses $(\ldots) \cdot{ }^{12}$

En general, todos los comentarios a la moda presentados en la prensa de Tenerife valoran especialmente los figurines que llegaban a la isla a través del Correo de la Moda cuyas estampas provenían, con mayor frecuencia, del periódico parisino Le Moniteur de la Mode, ${ }^{13}$ garantizándose de esta manera la preponderancia y el prestigio de los talleres franceses (VELASCO, 2016: 299-307).

En cuanto a los contenidos de los artículos, en general, se describían las primicias o modificaciones que adoptaba el vestido en cada temporada y se sugería a las tinerfeñas seguirlas, describiendo las ropas y aportando figurines para proponer cómo cortar y confeccionar los vestidos, adaptándose a los tejidos, colores y complementos existentes en la isla. Recordemos que todo el periodo isabelino y a grandes rasgos, está presidido en las prendas interiores por el corsé, cada vez más ajustado al cuerpo gracias a la introducción en 1829 de ojetes de acero en la espalda para deslizar una cinta que permitiese un buen prensado. Sobre una ligera enagua (en forma de falda o calzón), se ajustaba una crinolina, -otra enagua más rígida realizada originalmente por crines de caballo (o sustituidas por hilos de lana, las más humildes) - con el fin de aportar volumen (AvELLANEDA, 2007: 101105) que desde 1840 y perviviendo hasta 1870, fue sustituida por el miriñaque, una estructura de varios aros de acero concéntricos en sentido piramidal, abombado hasta la cintura, que se iban pasando por el interior de una enagua gruesa, muchas veces en ligamento de sarga.

Sobre la ropa interior, un vestido de amplio vuelo para posarse sobre el miriñaque. Habitualmente de seda, solía llevar blondas de encaje como adorno; en el caso de ser vestidos de salir o de fiesta, poseían gran escote cuadrado y mangas de jamón abullonadas hasta el medio antebrazo y rematadas por encaje. Si era un traje de invierno o de paseo, se cerraban en cuello de caja con encajes, blondas (bertas) o diversa pasamanería, y la manga ajustada en el antebrazo, pero abierta en pagoda hacia la mano y cerrada con tules y encajes superpuestos. Sobre la espalda, un foulard de lana de cachemir, a manera de pañoleta (a veces con hilo de seda), o un fichú de encaje, una prenda piramidal que cae sobre la espalda y se anuda sobre el escote (SPOSITo, 2016: 128-133). Sobre la cabeza, peinados caprichosos ornados con plumas o peinetas entreveradas y una progresiva evolución del sombrero. Los zapatos -de cuero y tacón bajo, con los amarres sobre el forro abrochados con botones-, comienzan en este periodo a conocer

12 Carmela. El Eco del Comercio, 21 de noviembre de 1863, Santa Cruz de Tenerife, 3.

13 Este periódico se editó entre 1843 y 1913, siendo, tal vez, el de mayor influencia en Francia y en el extranjero por la cantidad y variedad de figurines que aportaba entre sus páginas, divulgando en cada temporada nuevas modificaciones del vestido (a veces, mínimas) que aseguraban el flujo comercial de la moda, lo que denominamos desde entonces tendencias. Para acceder a su lectura a través de la Bibliothèque National de France [en línea]. Disponible en: https://data.bnf.fr/34444051/le_moniteur_de_la_mode_paris_/ [Consulta: 02/07/ 2020] 
su despegue desde el punto de vista del diseño, elevando ligeramente el tacón (Figura 6).

Suele cerrar el vestido femenino, conforme avanza la década de los cincuenta, una prenda proveniente de la moda masculina: el paletó. Se trata de un abrigo de lana gruesa pero ajustada a la cintura, como si se tratase de una levita, que llega hasta la rodilla, con la misma función de abrigo que cumplía el sobretodo de lana, una prenda más suelta, popular y sin estructura fija. No podemos olvidar que los vestidos femeninos estaban salpicados de aplicaciones de pequeñas joyas prendidas con gracia por el vestido, que denotaban el poder económico y social de la mujer, prendas de las que, a duras penas, ha llegado hasta nosotros el broche de abrigos o chaquetas. Con lo que hemos señalado, hemos realizado una descripción ideal, sujeta a muchísimas variantes.

La moda masculina (RIELLO, 2016: 66) para uso diario, estaba sujeta a menos cambios y continuaba la tendencia abierta durante el Directorio; es decir, un traje de tres piezas, de chaqueta, chaleco y calza hasta media rodilla que en pleno Romanticismo se transforma en pantalón. Si bien originariamente dichas calzas eran de tonos más claros, hacia 1840 se impone el color negro. Cubriendo la indumentaria para las grandes ocasiones el paletó, o la levita, en torno a 1860, que podía ser aún más baja, ligeramente por debajo de la rodilla, pero corta por delante, hasta la cintura. Al emplearse levita, esta solía caer sobre el chaleco al no emplearse chaqueta. Las camisas frecuentemente eran de cuello caja y abotonadas, a las que se añadían cuellos altos postizos, de formato variado y de telas rígidas sobre una estructura de cartón (los casos más económicos) o entretelas de lana engomadas, más flexibles, aunque firmes y envaradas, al igual que los puños de botones y las pecheras yertas que asomaban bajo el chaleco, anudadas con una cintilla a la espalda (Figura 7).

Esta descripción sucinta de las modas mayoritarias en el arco cronológico 1833-1868 se ajusta a la forma de vestir en Santa Cruz y permite comprender mejor el contenido de los artículos de moda divulgados en la prensa. Citaremos algunos ejemplos para ilustrar la cuestión.

En abril de 1853, el Noticioso de Canarias recoge un artículo de la prensa madrileña, en el que se plantea que, a falta de novedades procedentes de París, el final de la primavera languidece así:

(...) No habiendo surtidos nuevos de que poder hablarte, te diré, en punto, a hechuras, que los cuerpos con faldetas se han enseñoreado violentamente del campo de la moda, y que afuer de conquistadores, no sufren rivales. Sea el cuerpo del vestido abierto o cerrado, lleva indispensablemente su acompañamiento de faldetas (...) Las mangas pagodas, abiertas por el lado, no ceden el puesto si bien admiten ciertas modificaciones $(\ldots . .)^{14}$

El Instructor y el Recreo de las Damas de Santa Cruz de Tenerife, se hace cargo exclusivamente de ese tipo de textos, es decir, de los que relatan las modas de Madrid como reflejo de París, tal y como venía recogido en la prensa nacional. Su

14 Sin firma, «Cartas a Julia», El Noticioso de Canarias, 20 de abril de 1853, Santa Cruz de Tenerife: 3-4. 
valor consiste, por tanto, en la aportación de ideas sobre el largo de las mangas, el bajo de las faldas, miriñaque sí o no, pero nada de crítica, tal vez por considerarla innecesaria en la creencia de que a la mujer sólo le interesaba el detalle y no el fondo. Grave error, pues muchos de esos artículos copiados de Madrid eran escritos por mujeres que, de forma indirecta, dejaban caer ideas estéticas. En la noticia siguiente se piden excusas por no poder ofrecer en el periódico nuevas tendencias porque los figurines no cambian de un día para otro:

(...) Aunque en la capital de Francia, en París que es a la vez la capital del mundo elegante, no es posible que la fantasía varíe de tal manera y con tal rapidez que apenas se deje tiempo suficiente a las modistas para confeccionar los adornos y vestidos conforme a los últimos figurines $(\ldots){ }^{15}$

En el mismo sentido, apreciamos una defensa del miriñaque, tan criticado por la prensa y muchas mujeres debido a su incómodo tamaño, justo antes de que se iniciase su declive como estructura básica del vestido:

(...) Empezamos por el miriñaque, útil absolutamente indispensable en la presente época por más que algunos detractores le hayan declarado la guerra. Para que el miriñaque vista bien y no se convierta en ridículo, es preciso no sea exagerado. Nuestras abuelas llevaban sus vestidos ahuecados por medio de tontillos, y es preciso que los ahuecadores de hoy no excedan el volumen de aquellos (...). ${ }^{16}$

Otro ejemplo del tenor de este periódico es lo que sigue:

“(...) Los piqués ingleses están más de moda que nunca para negligés de casa y vestidos de campo. Nada hay de tan buen gusto. Los encajes se llevan con profusión, toda la ropa blanca se adorna con ellos $(\ldots) .{ }^{17}$

En la década de los años 60, el concepto del vestir no cambia de forma radical. Quizás apreciamos unos comentarios algo más atinados en el planteamiento de las novedades, pero no en la intención. Cobra interés en el Eco del Comercio y en el El Mensajero de Canarias, editado por Baltasar Mójica, la repercusión de los artículos publicados sobre moda en El Correo de la Moda de Madrid por Aurora Pérez Mirón, que como hemos indicado, es el seudónimo de Joaquina García Balmaseda, una de las escritoras más notables del siglo XIX español. En septiembre de 1865, publicaba un avance de la temporada:

(...) La moda de trajes completos de un mismo color, es decir, enagua, falda y paletot de una misma tela continuará muy en moda durante el otoño, pero es necesario saber escoger los colores cuando se trata de hacer un traje complemento, porque no todos son aceptables para dicho objeto. El marrón, el gris, y el violeta son los colores que se adaptan para traje completo, y aún debe tenerse presente que el violeta no

15 Sin firma, Modas, El Instructor y el Recreo de las Damas, 30 de noviembre de 1857, Santa Cruz de Tenerife: 1.

16 Sin firma, El Instructor y el Recreo de las Damas, 20 de enero de 1858, Santa Cruz de Tenerife: 1-2. 17 Sin firma. El Instructor y el Recreo de las Damas, 20 de julio de 1858, Santa Cruz de Tenerife: 1-2. 
hace buen efecto si no se le oscurece un poco adornándole con negro (..... ${ }^{18}$

Poco tiempo después:

La completa reina, la hija del capricho en vestir, esa matrona que llamamos moda, ha introducido, amigas mías, una gran reforma en nuestro traje. (...). Cayó la cola; amigas mías, esto es, se considera del peor gusto el uso del traje largo que pase de la orla del talón por la sencilla razón de haber quedado esa moda como distintivo de las mujeres del mal vivir (...). En cuanto al miriñaque ya he dicho que no se usa por la gente decente, y que la moda de más tono, es el vestido unido, sin amplitud a la imperial: adorna mucho después del cambio de aquella monstruosidad. Hoy no se ven en las reuniones, espectáculos ni en ningún lugar público, mujeres con crinolinas $(\ldots)^{19}$

Estas serían las dos líneas editoriales en la prensa tinerfeña, un debate entre la tradición, condición de lo eterno, y la moda, condición de lo fútil. La victoria, poco a poco, se inclinaría hacia el éxito social que supone vestir bien y relatarlo será la misión de las crónicas de moda que se impondrán en todos los rotativos.

\section{LA VIVENCIA DE LA MODA EN SANTA CRUZ DE TENERIFE, 1833-1868}

La materia que abordaremos en este apartado ya no está relacionada con el campo conceptual, sino con la práctica de la moda. Gracias a la sólida implantación de la prensa en la capital hemos podido rastrear el relieve que el comercio relacionado con la indumentaria $\mathrm{y}$, en general, cualquier manifestación que podríamos asociarla al lujo, alcanzó entre nuestros antepasados. Llama la atención que después del tráfico mercantil de vapores, lo más destacado en las gacetillas de publicidad es la venta comercial de moda, por encima de la alimentación (es una percepción, en un futuro, sería interesante una estadística), dos mercancías que curiosamente llegaban a compartir espacio en la misma tienda. La presencia de la moda podríamos dividirla en varios sectores. En primer lugar, la profesión de sastre o modista, que, según la prensa, era mayoritariamente masculina, aunque seguro que con un buen número de oficialas no registradas en estos medios. En segundo lugar, abordaremos el género vendido en las primeras tiendas de modas que hemos podido rastrear, así como el tipo de indumentos más populares. Por último, nos aproximaremos a los complementos de moda, que también llegaron a ocupar un espacio interesante en la ciudad.

Con todo ello, pretendemos trazar un perfil de investigación que pueda ser útil para la construcción de un relato veraz sobre la historia de la moda en Tenerife y en Canarias, superando la especulación que se deriva del mero estudio a través de los retratos o las fotografías, que no siempre revelan la novedad de la

18 Aurora Pérez Mirón, Revista de Modas, El Mensajero de Canarias, 29 de septiembre de 1865, Santa Cruz de Tenerife: 3.

19 Aurora Pérez Mirón, Revista de Modas, El Mensajero de Canarias, 17 de enero de 1866, Santa Cruz de Tenerife: 3. 
moda, mutante y voluble.

En cuanto a la sastrería, la primera noticia que se divulga en Santa Cruz anuncia a un sastre «peninsular» que se establece en el Puerto de la Cruz en 1836 llamado Antonio Tinoco, pero que atiende a la clientela de Santa Cruz, ${ }^{20}$ y aunque su nombre no hemos podido constatarlo más adelante, sí aparece registrado el almacén de Rafael Tinoco (¿un hermano?) en la calle Cruz Verde $\mathrm{n}^{\circ} 21$, en la capital, donde vende «cintas de ballenas, cortes de vestidos de seda y algodón de mayor gusto, cortes de chalecos de seda, flores artificiales (...)». ${ }^{21}$ Más tarde, en 1855 se registra otro sastre, Leocadio Álvarez, que abrió su establecimiento llamado $\mathrm{La}$ Peninsular, algo inusual, porque hasta inicios de la década de 1850 los comercios carecían de nombre propio y solo eran citados como almacenes bajo el nombre de su propietario. El anuncio reza así: «La Peninsular Sastrería. Leocadio Álvarez acaba de llegar de la Península ofrece al público su establecimiento en la calle de Cruz Verde número 12 y al mismo tiempo sus trabajos con la perfección que tiene probada en los puntos en que se ha hallado establecido, tanto en las prendas de paisano como de militar». ${ }^{22}$

Pocos años después, constatamos la presencia de otro negocio, bajo el título de Sastrería Francesa Bernard y Labory que garantizaba realizar ropas confeccionadas con telas de las ciudades francesas de Sedán (Ardenas) y Elbeuf (Sena Marítimo), que en el siglo XIX tenían fama por la producción de tejidos ya industrializados de alta calidad. ${ }^{23}$ Asimismo, en 1863 verificamos la primera sastrería o tienda de costura con escaparate y exposición pública, visibilizando las labores del interior, lo que hasta entonces no era común: «Tienda de Modista. Se acaban de recibir dos modelos de sombreros (gorras) que están de manifiesto en la vidriera de este establecimiento; de las mismas formas de las telas, clases y gustos que las Sras. le favorezcan. También se confeccionan con la mayor elegancia trajes de sras. y niños, abrigos y adornos, gorritos (tocados), faldas para bautismo, sombreros de paja y de tela, recibiéndose encargos y composturas. Calle de Santo Domingo, $\mathrm{n}^{\mathrm{o}} 1 » .{ }^{24}$ No obstante, es seguro que existieron muchos talleres de costura no registrados por la prensa, pues el hábito social más extendido era encargar la confección de las prendas, aunque es cierto que conforme avanza la década de 1850, van apareciendo comercios dedicados no solo a la venta de ropa, sino a la moda como tal.

Sin embargo, donde mejor se aprecia el impacto social y la evolución del gusto por vestir es la progresiva apertura de comercios de moda. Para todo el reinado isabelino podemos distinguir dos etapas, aunque sin una frontera cronológica exacta. Durante la primera, con límite aproximado en 1855, la venta de tejidos formaba parte del género de los almacenes, conocidos mayoritariamente por la calle y número de gobierno en el que se alojaban, y/o por el nombre de su propietario. También era común registrar el indumento más vendido, que,

20 Publicidad, Boletín Oficial de Canaria, 22 de junio de 1836, Santa Cruz de Tenerife: 4.

21 Publicidad, El Eco del Comercio, 6 de febrero de 1858, Santa Cruz de Tenerife: 3-4.

22 Publicidad, El Eco del Comercio, 14 de noviembre de 1855, Santa Cruz de Tenerife: 4.

23 Publicidad, El Eco del Comercio, 16 de enero de 1858, Santa Cruz de Tenerife: 3.

24 Publicidad, El Progreso de Canarias, 23 de junio de 1863, Santa Cruz de Tenerife: 4. 
aunque hoy nos pueda sorprender, en los años centrales del siglo era el sombrero, tanto para hombres como para mujeres. Decimos que puede sorprendernos, porque pensamos que sería otro indumento (el vestido), pero, al fin y al cabo, era el que más uso y desgaste tenía. Si bien muchos eran confeccionados a precios económicos por artesanos locales que poca trascendencia tenían en la prensa (aparecen discretamente en algunos anuncios), para las clases medias eran de lana prensada, que conocemos como fieltro. Para las clases más populares la prenda por excelencia del siglo XIX fue la cachorra, que no se trataría de un sombrero de fieltro tipo homburg de copa alta y truncada, o tipo bowler, como hoy se identifica en el folclore y la etnografía canaria, sino de una boina plana, o beret, como señala en un anuncio de 1857, donde se define el indumento: «cachorras de copa plana y redonda». ${ }^{25}$

Entre los primeros negocios dedicados al despacho de indumentos, pues el término moda parece prematuro, figura el almacén de Juan Vensano (1837) y el de Antonio Morello (1838), en la calle del Castillo n 46, que vendía sombreros de fieltro. ${ }^{26}$ En el almacén de la calle del Clavel n ${ }^{\circ} 10$, en 1842 , se observa un «surtido de sombreros para hombres y niños, gorras de señora, telas de seda para vestidos, cortes de chaleco, chales, manteletas, pañuelos y cuellos bordados, guantes de seda para señora y de piel para caballero, mantillas de tul de seda, botas y zapatos de todas clases para hombres, señoras y niños, cordonallo para ribete y botones de seda. Todo al mejor gusto, de última moda y a precios equitativos». ${ }^{27}$

A mediados de los años cincuenta aumentan nuevas menciones de almacenes que venden tejidos y todo tipo de productos de mercería, generalizándose la oferta de confección. En el almacén de Mr. Honneger en la Plaza de la Constitución (actual de la Candelaria) que hallaban a disposición «pañuelos de madras y tulares a todos los precios, corbatas tulares, corbatines, sobretodos de muselina de lana y casimir, cuellos de camisas, delanteras de camisas bordadas, driles de hilo puro, id. de algodón, sarasas imitación de piqué (...) batistas con encaje. Gorras para niños, esclavinas y bertas última moda (...) corsés mecánicos (...) vestidos de percales de Alsacia (...)». ${ }^{28}$ Como vemos, los productos vendidos en la capital canaria eran de primera calidad y sofisticados: tules (obviamente en aquella época, de seda), algodones madras (estampación a cuadros), sarasas o tejidos de algodón suaves y estampado floral, etc, siguiendo el gusto de la década de 1840 en que triunfaba la riqueza de las bertas, encajes que adornaban los escotes, mangas o espaldas de los vestidos. Otros almacenes fueron los de Juan Gutiérrez de León en la calle de la Luz (luego del Sol, actual Dr. Allart) o de Bosch y Compañía, en frente del Teatro Principal (actual Guimerá).

Sin embargo, hacia 1855 se produce una situación muy interesante. Sin un motivo aparente, algunos almacenes, cuya apertura no hemos podido fijar, comienzan a adoptar nombres comerciales. Es decir, que a pesar de vender otros productos asociados al lujo, como enlatados, vinos o champagne, se especializaron

25 Publicidad, $L a F e, 5$ de abril de 1857, Santa Cruz de Tenerife: 4.

26 Publicidad, La Aurora, 28 de marzo de 1838, Santa Cruz de Tenerife: 4.

27 Publicidad, Boletín Oficial de Canarias, 23 de julio de 1842, Santa Cruz de Tenerife: 4.

28 Publicidad, El Noticioso de Canarias, 26 de abril de 1854, Santa Cruz de Tenerife: 4. 
no sólo en el mundo de los textiles y la mercería, sino en la venta de vestidos, pantalones, chalecos, etc, ya confeccionados, lo que presupone un comercio de mercancías procedentes del exterior, como afirman algunos testimonios, adquiridos de fábricas en Sabadell y Tarrasa en Cataluña, Alcoy en Alicante, o de lugares como Béjar (Salamanca) o Ezcaray (La Rioja), ${ }^{29}$ que desde el siglo XVIII tenían prestigio por la fabricación industrial de paños. Pero en las tiendas que vamos a comentar, como en todas, cuando se quería publicitar un producto asociado al vestir de moda, se anuncia como llegado de París, y en el menor de los casos, de Londres o Alemania (sin especificar origen).

Algo de verdad habría, sin duda, pues una de las líneas marítimas de mayor prestigio era la que unía los puertos de Santa Cruz de Tenerife con Marsella (y escalas habituales en Mogador -actual Esauira, Marruecos-, Gibraltar y Alicante), consignada por Hardisson Hermanos, con el vapor Marocain como principal protagonista, al menos entre 1858-1868. El extraordinario desarrollo de la sericicultura en la Provenza y el monopolio de la producción de tejidos sederos en Lyon, favorecieron desde el siglo xvi el puerto de Marsella y la exportación de ese textil. Ello justifica que el tejido más vendido por los comercios santacruceros fuese la seda negra, aunque siempre se añade que también la había de otros colores.

En 1855 comienza a publicarse como espacio para la moda el almacén de José Picó, en la calle del Castillo n ${ }^{\circ} 25$. Dos años después, en enero de 1857 ya lo vemos anunciado como La Barcelonesa, especializada, entre otras mercancías, en "pantalones de casimir superior, ternos de id., cortes de seda para vestidos de señora, negros y de colores, chalecos de moiré [muaré] y terciopelo (...) calcetines de algodón listados, su mayor parte elásticos, charoles y tafiletes (...)». ${ }^{30}$ También cucharas de peltre, cuerdas para violines, etc... Las tiendas, para reforzar esa idea, destacaban los vapores por los que llegaba el género; además del mencionado Marocain, destacaba también el Byzantin y el Egyptien. La mercancía no solía variar. En 1861, entre otros productos, ofrecía delanteras de camisas adornadas, cachuchas (gorras) de paño para niños, corbatas de muaré negros y de colores, pañuelos de seda para personas o champagne en botellas pequeñas. ${ }^{31}$

El mismo año 1855 el establecimiento abierto por Juan Ignacio Hernández en la calle de San Francisco ofrecía gran oferta de cachorras, sombreros de felpa negra ${ }^{32}$ de París, ingleses impermeables y de paja franceses; ${ }^{33}$ sin duda, en los dos últimos se refiere a algún modelo antiguo de pescador, y de canotier. Un año después, también cambia la estrategia y a comienzos de $1858^{34}$ da a conocer su almacén bajo el nombre de La Elegancia, que desde los inicios se especializó en la venta de sombreros, sobre todo de Liorna, nombre referido a las fábricas de sombreros de Livorno, en la Toscana italiana (hasta el siglo XIX se empleaba en

29 Publicidad, El Eco del Comercio, 2 de abril de 1857, Santa Cruz de Tenerife: 4.

30 Publicidad, El Eco del Comercio, 22 de enero de 1857, Santa Cruz de Tenerife: 4.

31 Publicidad, El Eco del Comercio, 21 de agosto de 1861, Santa Cruz de Tenerife: 4.

32 Se denominaba felpa, además del tejido de algodón, al revestimiento en seda negra que envolvía ciertos sombreros de fieltro, ganado un aspecto satinado y, por lo tanto, con apariencia más lujosa.

33 Publicidad, El Eco del Comercio, 10 de noviembre de 1855, Santa Cruz de Tenerife: 4.

34 Publicidad, El Eco del Comercio, 27 de enero de 1858, Santa Cruz de Tenerife: 3. 
España el topónimo antiguo), que producían sombreros homburg de fieltro y de paja. También vendía cachorras finas (obviamente se refiere a boinas, o beret, o beretas, de lana fina) y zapatos de goma para señoras. Al parecer, en el caso de estos últimos, se trataba de un zapato con ese tipo de suela pegada a un empeine de lona con cordoneras que, además de resultar cómodos para personas con problemas en los pies, antecede al uso del calzado deportivo. En 1861, además de ese tipo de productos, se hallan manteletas y mantillas, encajes de seda negra, cinta de acero para miriñaques, elástico para sombreros, medias blancas para niñas, y otros géneros (Figura 8). ${ }^{35}$

El tercer gran comercio de moda careció de nombre comercial y fiel a la nomenclatura tradicional, mantuvo el de su propietario, d. Faustino de Armas, y se situaba en la Plaza de la Constitución esquina a la calle de Cruz Verde, popularmente conocida entonces como calle de las Tiendas, manteniendo su actividad comercial hasta el final del periodo que estudiamos, 1868. Entre las prendas que vendía encontramos:

«(...) sobretodos de crespón de la China, bordados llanos y charoles (...) bufandas de varias clases para caballeros y señoras, capotitos de lana para niños, delanteras bordadas para camisas, cortes de ternos y pantalones (...) cortes de chalecos de seda del mayor gusto, cortes de vestidos con volantes y escoceses de moiré Antique, manteletas negras y de colores de la última moda $(\ldots) » .^{36}$

Como vemos, tejidos finos y de moda; en este caso nos llama la atención la venta de crepé (crespón) de China, ${ }^{37}$ un tejido que comenzó a producirse de forma industrial en Francia, alcanzando gran éxito entre los y las modistas de mediados del siglo, y que posiblemente llegó a Santa Cruz en los vapores de la línea de Marsella. Podemos, asimismo, apreciar que en este comercio se vendía por igual rollos de tela y ropa confeccionada. En 1865 el tipo de prendas no habría variado. Ofrecía «(...) vestidos de seda, cortes de pantalones, chalecos de última moda, paletotes de seda para sra., sobretodos de granadine de colores y negros (...)»; también en este caso, llama la atención las prendas muy de moda en París, como el denominado paletot, abrigo de lana fina ceñido a la cintura, amplias solapas y que llegaba a la rodilla, en una versión más holgada para mujeres, o la gabardina (grandine) de lana, un tejido resistente que al tener el doble de densidad la urdimbre sobre la trama, facilitaba prendas menos ajustadas pero muy flexibles a la vez que abrigadas, haciéndolas ideales para la calle.

Otros almacenes se fueron abriendo en Santa Cruz, ofreciendo géneros variados, como calzado y sombreros, cuya relación es larga y no aportaría novedades especiales. Sin embargo, en la segunda mitad de la década de 1860 se experimenta un ascenso del número de comercios que venden modas. En 1864 comienza a anunciarse el almacén Valle de Taoro, que acababa de recibir por los vapores Tharsis y Pelayo, de las mejores fábricas de París, Lyon y Marsella, un surtido de vestidos de seda negra y colores, gorras para señora, terciopelo

35 Publicidad, El Eco del Comercio, 21 de agosto de 1861, Santa Cruz de Tenerife: 4.

36 Publicidad, El Eco del Comercio, 20 de febrero de 1859, Santa Cruz de Tenerife: 4.

37 Para la consulta sobre los tejidos, recomendamos la lectura de SPOsito (2014). 
negro, sombrillas, corsés, miriñaques, cinturones, sobretodos de seda bordados, sombreros de pelo y cachorras a la moda de París, entre otros artículos. ${ }^{38}$ Esta tienda se convertiría en un almacén especializado en el lujo; un año después anuncia sombreros y cachorras, chalecos de seda, paraguas, sombrillas de color, encajes de seda blancos y negros, tartalana [tartanes], hebillas de cinturones y objetos de lujo, juegos de porcelana para café, dominó, ajedrez, cuchillos y tenedores de mango plateado, vestidos negros de grós, muselinas, sarasas, etc. ${ }^{39}$ El gros, un vestido mayoritariamente producido en Tours, tafetán de seda o algodón un tanto más rígido, daba un resultado visual ligeramente satinado y elegante, y fue el tejido más destacado por las revistas de moda francesas en los últimos años del reinado de Napoleón III y Eugenia de Montijo. Su venta en Santa Cruz asegura que esta tienda era realmente un comercio de modas (Figura 9).

En 1868, último del reinado de Isabel II, apreciamos un aumento de tiendas de textiles y/o de moda, entre ellos el almacén de Ballester y Martí, en la calle del Sol $\mathrm{n}^{\mathrm{o}} 2$, con venta de driles, muselinas y como prendas confeccionadas, calcetines, ${ }^{40} \mathrm{O}$ el almacén de paños de José María Palazón, en la calle del Castillo nº 21, que vendía tejidos «de las mejores fábricas de París». ${ }^{41}$ Otras tiendas de paños irán surgiendo ese mismo año, como Elegancia y Equidad, almacén de tejidos de Ignacio Cantero, establecido en la calle del Castillo $n^{\circ}$ 9, que anuncia vender telas alemanas y francesas; ${ }^{42}$ la Casa Francesa de M. Emilio Bellanger, en la Plaza de la Constitución $n^{\circ}$ 9, probablemente un francés asentado en Santa Cruz de Tenerife, que expende paños y sombreros: «de lana, seda, algodón, paños, sombreros y efectos de moda de varias clases para señoras y caballeros». ${ }^{43}$ Por último, el almacén de Simón Lozano y Hermanos, situado en la calle del Castillo $\mathrm{n}^{\circ} 37$ ofrecía «(...) paños negros superior clase de las acreditadas fábricas de España y Extranjero (...). Un variado surtido de cortes pantalones franceses y alemanes, chalecos de seda, id. de algodón, sobretodos de seda, id. de cachemir, id. de lana. Fajas de seda, id. de estambre, id. de lana (...)». ${ }^{44}$

Por último, y asociado al mundo de la moda, los complementos se irán imponiendo poco a poco relacionados con la elegancia en el vestir. Aunque sería materia de otro trabajo, vemos cómo en esas tiendas se abrirá camino la perfumería. Por ejemplo, en el comercio La Elegancia en 1863 se venden «Agua de la Florida venida de New York, aceite de la sociedad higiénica, agua de flor de naranja para refrescos (...)». ${ }^{45}$ Igual de importante sería a apertura en 1865 de la relojería de Mr. J. Ladeveze, en la calle del Sol $\mathrm{n}^{\circ} 4$, que despachaba relojes ingleses, suizos de la marca Groselande, ${ }^{46}$ aunque lo más destacable sería la venta de joyas. El

38 Publicidad, El Eco del Comercio, 24 de febrero de 1864, Santa Cruz de Tenerife: 4.

39 Publicidad, El Eco del Comercio, 7 de enero de 1865, Santa Cruz de Tenerife: 4.

40 Publicidad, El Eco del Comercio, 18 de mayo de 1868, Santa Cruz de Tenerife: 4.

41 Publicidad, El Eco del Comercio, 29 de julio de 1868, Santa Cruz de Tenerife: 4.

42 Publicidad, El Eco del Comercio, 3 de agosto de 1868, Santa Cruz de Tenerife: 4.

43 Publicidad, El Progreso de Canarias, 3 de diciembre de 1868, Santa Cruz de Tenerife: 4.

44 Publicidad, El Eco del Comercio, 9 de diciembre de 1868, Santa Cruz de Tenerife: 4.

45 Publicidad, El Progreso de Canarias, 23 de junio de 1863, Santa Cruz de Tenerife: 4.

46 Hemos podido rastrear que efectivamente, existió esta marca y a comienzos del siglo xx poseía tienda en Madrid, pero no hemos conseguido averiguar más información. 
campo de la peluquería es menos conocido y precisa de estudios posteriores. Las escasas referencias son a establecimientos para caballeros, y en la mención a las señoras, se sigue la moda en la organización del cabello, frecuentemente ornado de pequeñas joyas o plumas, triunfando hacia el final del siglo, el sombrero; pero casi nada relatado sobre peluquerías femeninas. No obstante, VelAsco (2018: 49) en su estudio sobre la peluquería en la prensa española, señala que el para el gremio de peluqueros, la referencia sería Francia, gracias a las imágenes que de allí provenían. Y así debió ser en el caso de Canarias, pues al contrastar los figurines de moda franceses divulgados por la prensa local con las fotografías más antiguas, apreciamos que, en materia de cabello, desde Francia no se aconsejaba, se imponía.

A su vez, la fotografía irrumpió en la década de 1860 con fuerza en la sociedad tinerfeña gracias al establecimiento al público de varios fotógrafos y la realización de las carte de visite, retratos que se regalaban a seres queridos con el fin de transmitir una imagen a la posteridad, no de capturar un momento fugaz y cotidiano; es decir, el mismo concepto del retrato, solo que ahora extendido a un público mucho más amplio por ser más barata que un cuadro. En consecuencia, habrían de seleccionarse muy bien las prendas a ser vestidas para reflejar en la foto la moda del momento y, por lo tanto, la idea de éxito social. La fotografía de retrato, desde mediados de esa década y ya en la década de 1870, se convertiría en un acontecimiento social muy importante en todas las ciudades burguesas y en una fuente fidedigna para la historia de la indumentaria y de la moda, aunque se difunda en una cronología que escapa las limitaciones de este trabajo. Destaca el establecimiento a comienzos de 1865 de Santos María Pego, ${ }^{47}$ anunciando en $1866 \mathrm{su}$ establecimiento en la calle del Castillo $\mathrm{n}^{0} 10 .{ }^{48}$ Aunque sean escasos, los testimonios de ese periodo son verdaderamente extraordinarios. Pero fueron los hermanos Rafael y Bartolomé Belza y Monagas, naturales de Las Palmas pero de familia asentada en Tenerife, los que inauguraron un estudio de fotografía en Santa Cruz el año 1864, trabajando en solitario Rafael desde 1867. Como señala Carlos Gaviño, su especialidad fue el retrato, siendo los más notables para el estudio de la moda reflejada en la fotografía, alcanzado gran notoriedad social y éxito por sus magníficas creaciones, cruciales en los años posteriores al reinado de Isabel II (Figura 10). ${ }^{49}$

No podemos concluir sin señalar que muchas librerías de la ciudad vendían revistas de modas, más influyentes por los figurines que acompañaban, a veces con patrones, que por los textos descriptivos. En la Librería Isleña, en 1851, se despachaba El Correo de la Moda, con sus contenidos y figurines, ${ }^{50}$ también vendido en la Imprenta y Librería de la Viuda e Hijos de D. Vicente Bonnet. ${ }^{51}$ A partir de la década de 1860, fue frecuente que la prensa difundiese algunos periódicos

47 Publicidad, El Guanche,11 de febrero de 1865, Santa Cruz de Tenerife: 4.

48 Publicidad, El Insular, 25 de julio de 1866, Santa Cruz de Tenerife: 4.

49 Los Belza y su gabinete fotográfico. [Lopedeclavijo blogspot]. Santa Cruz de Tenerife]. Gaviño de Franchy, C., (septiembre de 2011) [en línea]. Disponible en: http://lopedeclavijo.blogspot. com/2011/09/los-belza-y-su-gabinete-fotografico.html [Consulta: 30/05/2020].

50 Publicidad, El Noticioso de Canarias, 20 de diciembre de 1851, Santa Cruz de Tenerife: 4.

51 Publicidad, El Eco del Comercio, 13 de junio de 1855, Santa Cruz de Tenerife: 4. 
de moda, justamente porque muchos de los artículos que se recogían provenían de ellos. El Eco del Comercio hacía campaña por La Moda Elegante Ilustrada. ${ }^{52}$ En 1865, El Mensajero de Canarias anunciaba que en el establecimiento de D. José Benítez, calle de San Francisco 14, se despachaba la misma revista, incluyendo las modas de París y Londres para confeccionar vestidos de señoras, señoritas y niños. También da dos patrones al mes para cortes de vestidos a tamaño natural y avisa que publica cada año 1.200 dibujos para bordados de tapicerías, crochet «y demás entretenimientos propios del bello sexo». ${ }^{53}$ En definitiva, que la publicidad de esas revistas en los comercios no sólo era beneficiosa para retener al público femenino en la prensa local, sino que al dirigir a las lectoras hacia las librerías se aprovechaba para promocionar lo que se denominaba literatura femenina.

\section{CONCLUSIONES}

En función de todo lo descrito, la primera evidencia es que Santa Cruz de Tenerife ni estaba apartada de los circuitos de la moda de su tiempo ni adoptaba una actitud pacata ante ese fenómeno. Al contrario. La más que evidente circulación de revistas de moda madrileñas que reflejaban las parisinas, la presencia constante de la importancia de la moda en la prensa, la variedad y riqueza de los textiles provenientes de las regiones productoras de mayor notoriedad de Francia y España, así como la existencia demostrable de sastrerías y talleres de costura alimentadas por buen género, así como el afianzamiento de comercios de moda en un concepto que se aproxima a una boutique (a la manera francesa de la época), reafirma la importancia de la moda en la vida de la ciudad.

También es verdad que no podemos garantizar exactamente qué modas alcanzaron mayor notoriedad. Si hacia 1830 en España (especialmente en Madrid) se produce el aumento de la falda con el miriñaque y hacia 1850 habían triunfado las bertas ornando los vestidos y los sombreros convivían con adornos de joyas y encajes enriqueciendo los peinados (PlAZA 2009: 169-190), no podemos afirmar hasta qué punto estas prendas fueron utilizadas por las mujeres tinerfeñas, especialmente porque el gran registro de la popularidad de la moda en la sociedad burguesa, la fotografía, solo gateaba en los últimos años del reinado. En cuanto a la moda masculina, lo único que podemos afirmar es que triunfaba el traje negro de lana fina y de tres piezas, cubiertos con sombreros de fieltro en los ambientes más exclusivos, y los trajes de paño de lana más gruesos con el predominio de la cachorra entre las clases más populares. Parece poco, pero gracias al desarrollo de Santa Cruz de Tenerife como ciudad burguesa y consecuentemente de la prensa, podemos apreciar notables testimonios sobre la vida cotidiana y su relación con la moda.

Si tuviésemos que recrear el imaginario de una tarde de domingo en la Plaza

52 Publicidad, El Eco del Comercio, 4 de enero de 1865; 6 de diciembre de 1865; 12 de junio de 1867, Santa Cruz de Tenerife: 4.

53 Publicidad, El Mensajero de Canarias, 23 de diciembre de 1865, Santa Cruz de Tenerife: 4. 
del Príncipe hacia 1860, pensamos en señoras luciendo vestidos negros de seda con miriñaque, pero con un diámetro limitado, recorrido por varias blondas de encaje y manga larga conducentes a un cuello alto rematado con encaje y el pelo ligeramente adornado nuevamente con encaje negro y alguna pluma. Las jóvenes, con vestidos sobre enaguas que caen sobre otro discreto miriñaque, tejidos de algodón madras o sarasa (a cuadros o estampado) o muselina en verano, con bertas adornando mangas pagoda y el escote cuadrado. Sobretodo de lana fina para ambas; en verano, un fichú de algodón y encaje, o de seda y encaje. El hombre, con escasa evolución, reservando el toque de moda para el tipo de sombrero o la gracia y calidad de tejido del corbatín. Durante el invierno, el uso del paletot. Las mujeres de extracción económica inferior, con vestidos sobre enaguas en lana con ligamento de sarga, y monillo, ${ }^{54}$ que en el mejor de los casos sería de algodón e incluso de muselina (Figura 11).

La moda siempre refleja a la sociedad que viste. A una ciudad burguesa, una moda burguesa. Santa Cruz de Tenerife, abierta al comercio, a recibir prensa escrita con artículos de opinión, revistas de moda pobladas de figurines, telas y pasajeros con destino a Canarias o de paso hacia América vestidos de forma moderna, esculpirían imaginariamente sobre la mente de las mujeres y hombres tinerfeños, la ilusión de transformarse en maniquís vestidos por prendas bien confeccionadas y a la moda, si es posible, a la manera de París. La progresiva apertura de ese extraño modelo de establecimiento, entre tienda de paños y mercería, con boutique, denota el paulatino interés de la sociedad tinerfeña por la moda, $\mathrm{y}$, en consecuencia, por la modernidad. De ello resultará el aumento constante del número de sastrerías y modistas, apreciable en la intensificación de anuncios en la prensa santacrucera. La moda, como producto de la revolución industrial, se sirve de los buques para transportar las mercancías en forma de telas o complementos que, llegadas al puerto, se transforman en un mundo de fantasía que hace confundir la Plaza del Príncipe con los Campos Elíseos. Et voilà! La magia de la moda.

\section{REFERENCIAS}

ACirón Royo, R. (1986): La prensa en Canarias. Apuntes para su historia, Santa Cruz de Tenerife, Confederación de Cajas de Ahorros.

Allen, J. (2002): «A través del Atlántico: el género del retrato y la isla», en J. Allen (comisario), Rostros de la isla. El arte del retrato en Canarias [1700-2000]. Casa de Colón/Cabildo de Gran Canaria/Cabildo de Tenerife/Gobierno de Canarias: 87-121.

Avellaneda, D. (2007): Debajo del vestido y por encima de la piel. Historia de la ropa interior femenina, Nobuko, Buenos Aires.

CASTRO BRUnetTo, C.J. (2017): «La moda francesa en la pintura canaria del siglo

54 Un tipo de jubón, en aquellos años, con mangas cosidas al hombro, que forma el torso de la indumentaria femenina. 
XVIII», Anuario de Estudios Atlánticos, 63, 063-013.

Cioranescu, A. (1979): Historia de Santa Cruz de Tenerife, vol. Iv, Servicio de Publicaciones de la Caja General de Ahorros de Santa Cruz de Tenerife, Santa Cruz de Tenerife.

Fraga González, C. (1999): El arquitecto Manuel de Oraá y Arcocha (1822-1889), Instituto de Estudios Canarias, La Laguna.

LozAno, J. (2000): «Simmel: la moda, el atractivo formal del límite», Espéculo. Revista de estudios literarios, 16 [en línea]. Disponible en: http://www.ucm. es/info/especulo/numero16/simmel.html [Consulta: 26/05/2020].

Martínez Viera, F. (2003): El antiguo Santa Cruz: crónicas de la capital de Canarias, Instituto de Estudios Canarios, La Laguna.

Plaza Orellana, R. (2009): Historia de la moda en España. El vestido femenino entre 1750 y 1850, Editorial Almuzara, Córdoba.

Riello, G. (2016): Breve historia de la moda. Desde la Edad Media hasta la actualidad, Editorial Gustavo Gili, Barcelona.

Simmel, G. (2014): Filosofía de la Moda, Casimiro Libros, Madrid.

Sposito, S. (2014): Los tejidos y el diseño de moda, Promopress Editions Barcelona.

Sposito, S. (2016): Historia de la Moda. Desde la Prehistoria hasta nuestros días, Prompress Editions, Barcelona.

Thion Soriano-Mollá (2011), «D. Joaquina García Balmaseda: una escritora isabelina al servicio de la mujer», Anales de Literatura Española, 23: 381-403.

Veblen, Th. (2015): «El vestido como expresión de la cultura pecuniaria», en J. Lozano (comp.), Moda. El poder de las apariencias, Casimiro Libros, Madrid: 55-71.

Vega de la Rosa, C. (1992): Marcos Baeza. Biblioteca de Artistas Canarios nº 11. Viceconsejería de Cultura y Deportes del Gobierno de Canarias, Santa Cruz de Tenerife.

Vega de la Rosa, C. (1995): La Isla Mirada. Tenerife y la Fotografía (1839-1939). Tomo I. Los Fotógrafos en el estudio, Centro de Fotografía Isla de Tenerife, Organismo Autónomo de Museos y Centros/Cabildo Insular de Tenerife, Santa Cruz de Tenerife.

Velasco Molpeceres, A.M. (2016): Moda y prensa femenina en la España del siglo XIX, Ediciones 19, Madrid.

Velasco Molpeceres, A.M. (2018): «Prensa de moda para hombres en España: intereses de clase y tendencias en la Guía del Peluquero (1873-1880)», Revista Internacional de Historia de la Comunicación, 10: 30-54.

Velasco Molpeceres, A.M. (2019): «Moda española. Del Renacimiento a Zara», Revista de Occidente, 455: 53-68. 


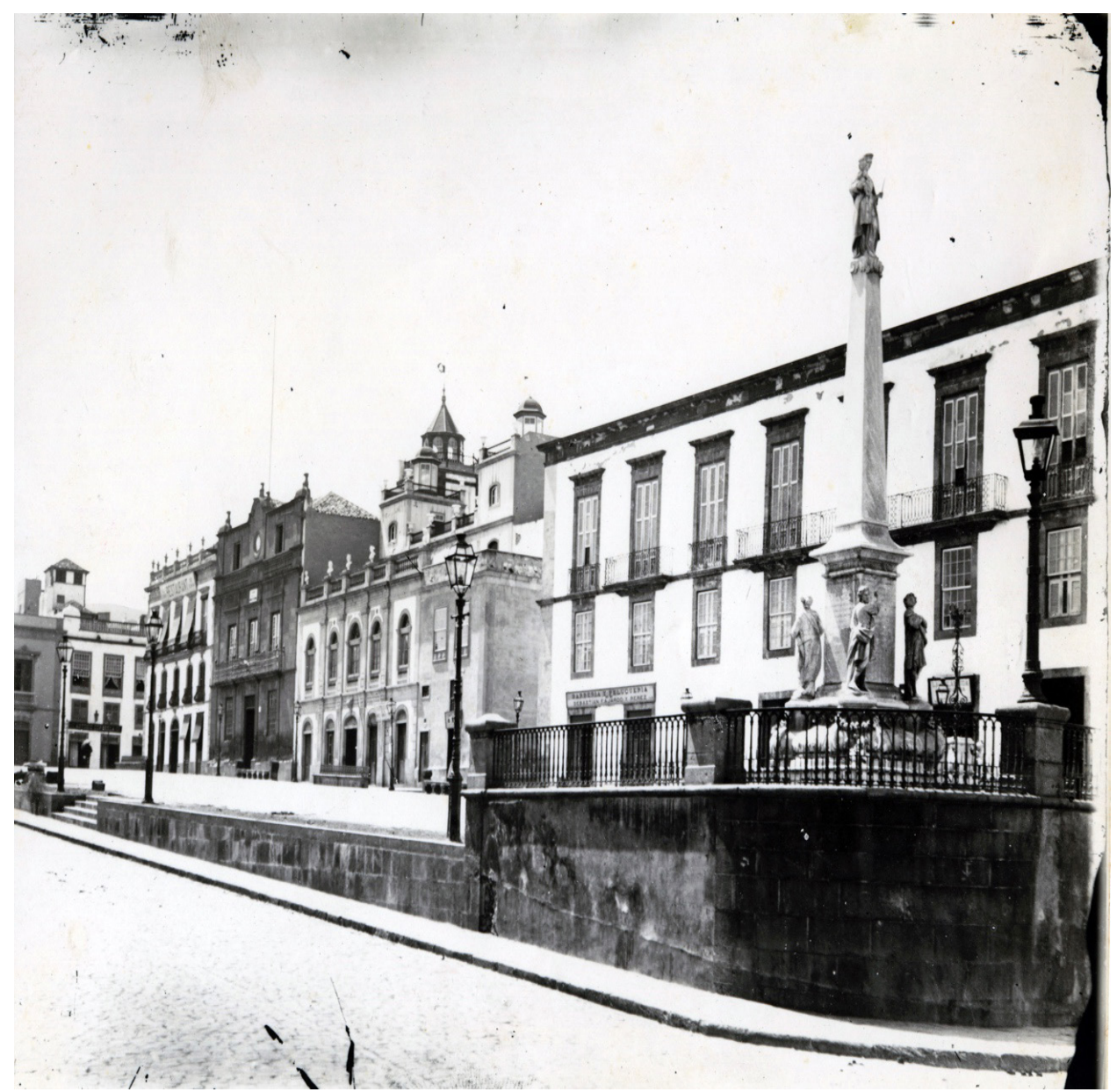

Figura 1. Fotografía anónima. Plaza de la Candelaria, Santa Cruz de Tenerife. Hacia 1890. Fuente: Archivo de fotografía histórica de Canarias, Cabildo de Gran Canaria, FEDAC (n registro: 000811). 


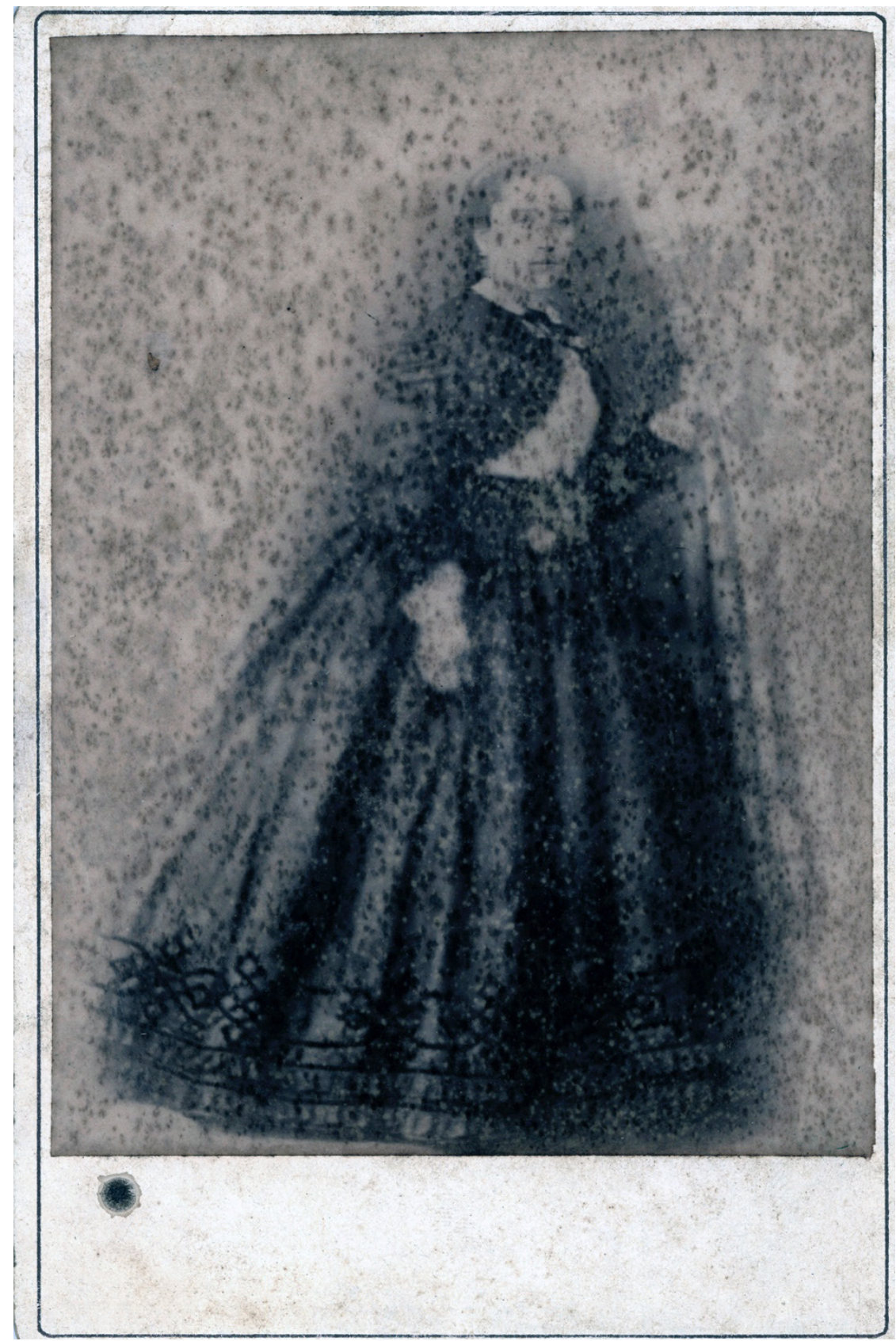

Figura 2. Fotografía anónima, vestido con miriñaque. «Junto a la cortina». 1865-1868. Tenerife.

Fuente: Archivo de fotografía histórica de Canarias, Cabildo de Gran Canaria, FEDAC ( ${ }^{\circ}$ registro: 5424$)$. 


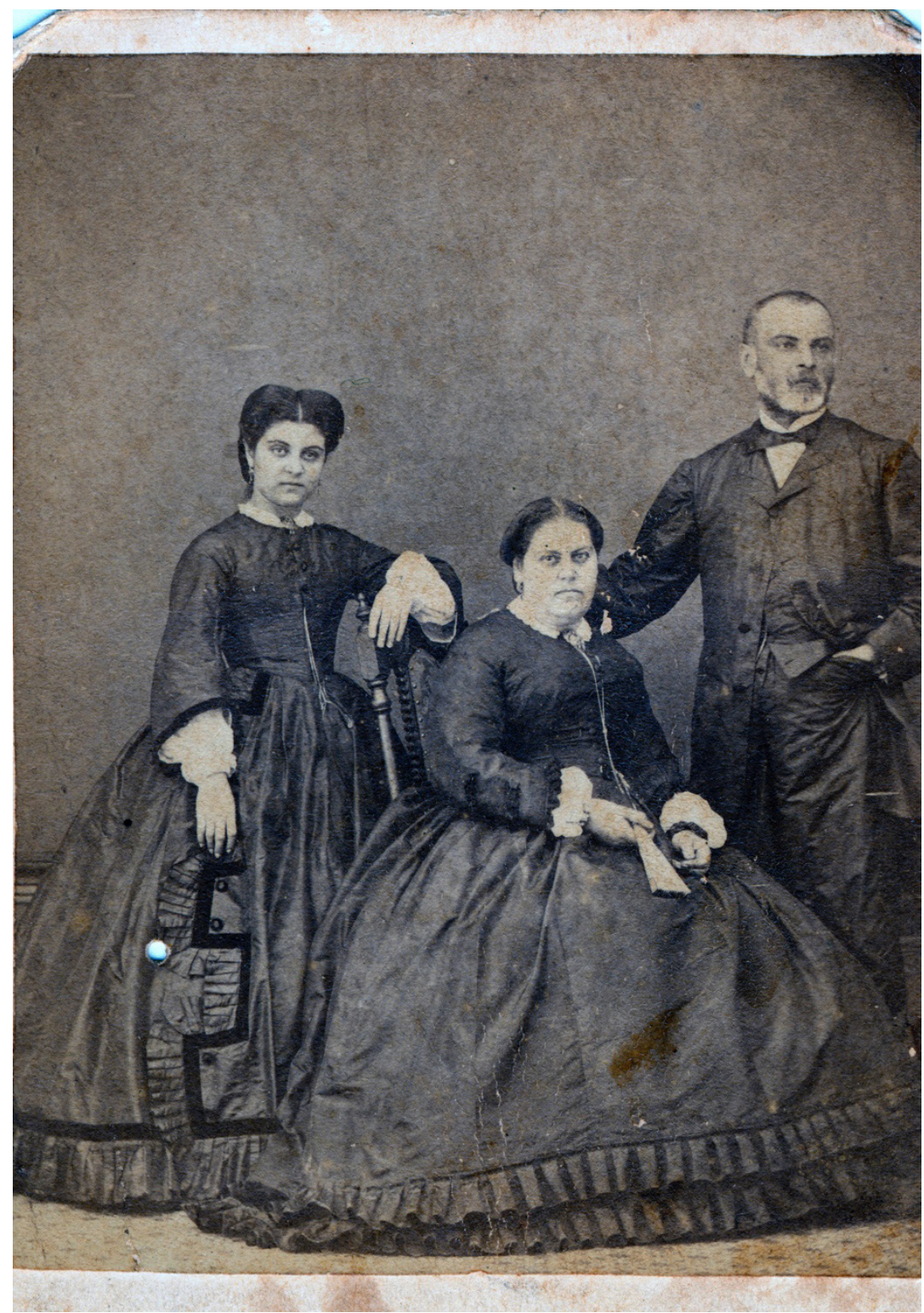

Figura 3. Fotografía de Antonio López Botas y familia. Santos María Pego. 1860-1870. Tenerife. Fuente: Archivo de fotografía histórica de Canarias, Cabildo de Gran Canaria, FEDAC $\left(n^{\circ}\right.$ registro: 11957$)$. 


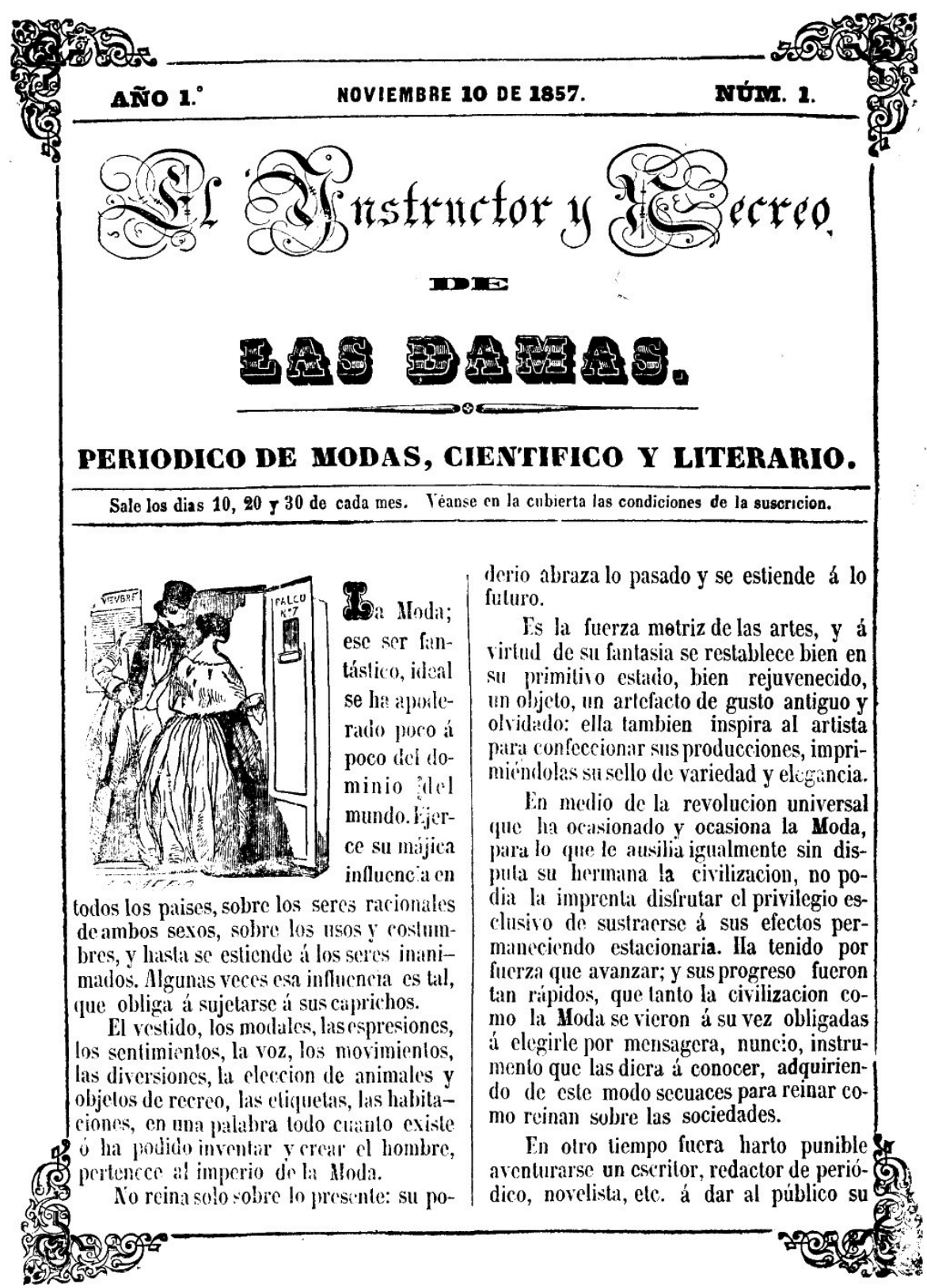

Figura 4. Portada de El Instructor y el Recreo de las Damas. Nº1. Santa Cruz de Tenerife, 10 de noviembre de 1857. Fuente: Jable. Archivo de Prensa Digital, Biblioteca Universitaria, ULPGC. 


DCO DEL CONHRCIO.

Periódico de Administracion, Literctura, Avisos é Intereses materiales.

Se publica ocho veres al mes. Se stacrilhe en la Imprenta de este periótico, en las Administraciones de Correos de esta Provincia, en la Habana casa de D. Manuel Cabezola

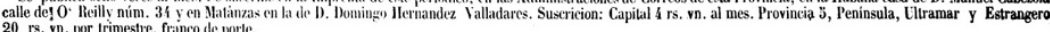
$20 \mathrm{rs}$. vn. por trimestre, france de porle.

\section{EL ECO DEL CONERTIO.}

Qe ha Judiferencix e) general.

En nuestro siglo se ha desarrollado un sentimiento que no es el egoismo, si se quiere; el espantoso, el
verdadero egoismo; no es tampoco ironía, acompañada de su punta de sarcasmo, es simpl emente la Indefeiferencia en todo.

Este sentimiento desconocido en las sociedades antiguas, hizo que ejecutaran tan grandes cosas, que al leerlas, y al no estar seguros de su
veraeidad, las tendriamos por fábuveraeidad, las tendriamos por fábu-
las mas 6 menos ingeniosas. No, mil veces no. Los antiguos ne copociemiento eminentemente contrario á la indiferencia que combatimos. Leonidas, Coriolano, Mucio Scévola, Régulo, Cincinato, y otros mil no obedecian mas que a su generosidad, su entusiasmo. Jamas desconfiaron de porvenir de la patria, jamas se acordaron de sí propio ni de su coaveniencia particular, jamas miraron con infiferencia el bien general, y siemprés á realizar lo que á veces vo promas que utopias.

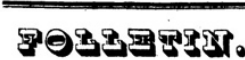

LEYENDA FANTASTICA.

FERNAN EL TROBADOR.

En valle ameno v frondis de azul y limpido ciclo,

que fertiliza un riachue

for su vista delicioso:

Do alegre de la avecil

y el amoroso cants

que deleita y maravilla:

Donde divinos vergeles

convidan con sh hermosura

à disfrutar la frescura

y el aroma de laureles:
Donde la vista tendiendo

bonde la vista tendien in

hasta la pequenia flor

en débil tallo meciendo

Do pasa feliz la vida

sin pena, sin amargura;

\section{Pues bien. Queremos mejor aquel del Ariosto} esceso de celo, aquella irreflexion, aquella earencia de exámen, que la fria indiferencia, que la sonrisa de láslima que se asona á los labios de
todos en la cpoca que atravesamos. Queremos mejor la candidez de aqueÎlos héroes antiguos, que la pedantesca fatuidad de los mezquinos in-
diferentes del dia.

Es cierto que entre aquellos mismos antiguos, se creó una escuela, pero esta estoicidad era mas bien malerial que moral. Consistia en el desprecio de todos los males que aflijen á la humanidad, consistia en vencer sus pasiones y en elevar el alma al mayor grado de grandeza y de sublimidad posible. Nada de esto se paree al Indiferentismo de nuestros dias. Espanta en serdad, los progresos que este raquítico sentimiento alean22 entre nosolros. Espanta, y caus cunde y se arraiga csa plaga en el corazon de la Jusentud. Que el anciano, henchido de goces 6 de desgracias, esclame como Caton al desgarrarse el
seno aj Virtud, no eres mas que un nombre! $\alpha \hat{~}$ que se envuelva en un glacial indiferencia, pase; pero la Juasomar la risa, el placer, el contento; la Juventud, esa l.crmosa primavera de la vida, diebe aparecer lozana como la for, bella como la anrora, entusiasta como los palautines

$=$

Alto castillo feudal

en su mitad se levanta,
de hermosa y soberbia plat

$y$ en lo fuerte sin igual.

Es del conide de Marbella

que det ville es poscertion.

de fiuzenan, sul copposa bella.

de Ge aquel sotico castil

ex el hada concantadora.

v en el vidle hasta la aulora

in campesine sencillo

Por ellta el Conde suspira:

pues con afan amoroso
a adora rendido exposo

y por su muger delira:

no tiene hária su marido.

que sil reposo ha perdido

por un bello trobador.

$A$ una niña, jiven y hern o a

cual del abril la mañana,

quedó en una edad te

Su dolor fiat tan profundo,

que al verse desamparada,

jóven y tan dessraciada

quizo dejar este mundo.
Oue la visa por do quiera

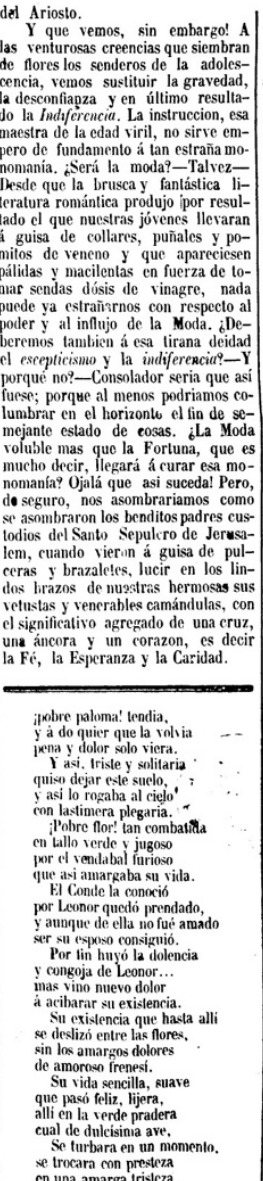

Ah! ojalá nos fortalezcan esas tres virtudes para combatir el vicio que aqui no hemos hecho mas que apuntar. ¡Ojalá, se destierre de entre nosotros ese flegma aparente, esa grasedad inutil y a veces perjudicial, que se halla en perpetua contradiccion con la Indiferencia juveniles ; Ojala que lugar á los vuelos del patriotismo del entusiasmo; pues asi, solamento asi, desaparecera esa inconcebible inmente y que nos impide caminar oo mas y del progreso, que son en e dia los dueños del mundo. Decia el sabio Rrasmo que la opinion y la aco titud de la juventud, era el verdadero barómetro de las ideas de un pais y el filósolo tenia razon. Hagamos pues de modo que la opinion la actitud de la nuestra estén conformes con los adelantos que nuestro pais reclama.

${ }_{6}$ PORQUE RL GARBON DE PIEDRA PERYANECE EN ALZA?

He aquí una cuestion que no podia menos de llamar la alencion de los especuladores ingleses, y que cada dia es de mayor importancia por el gran consumo de este artículo la imposibilidad de sustituirle con otro combustible.

Figura 5. Portada de El Eco del Comercio. Santa Cruz de Tenerife, 19 de noviembre de 1853. Fuente: Jable. Archivo de Prensa Digital, Biblioteca Universitaria, ULPGC. 


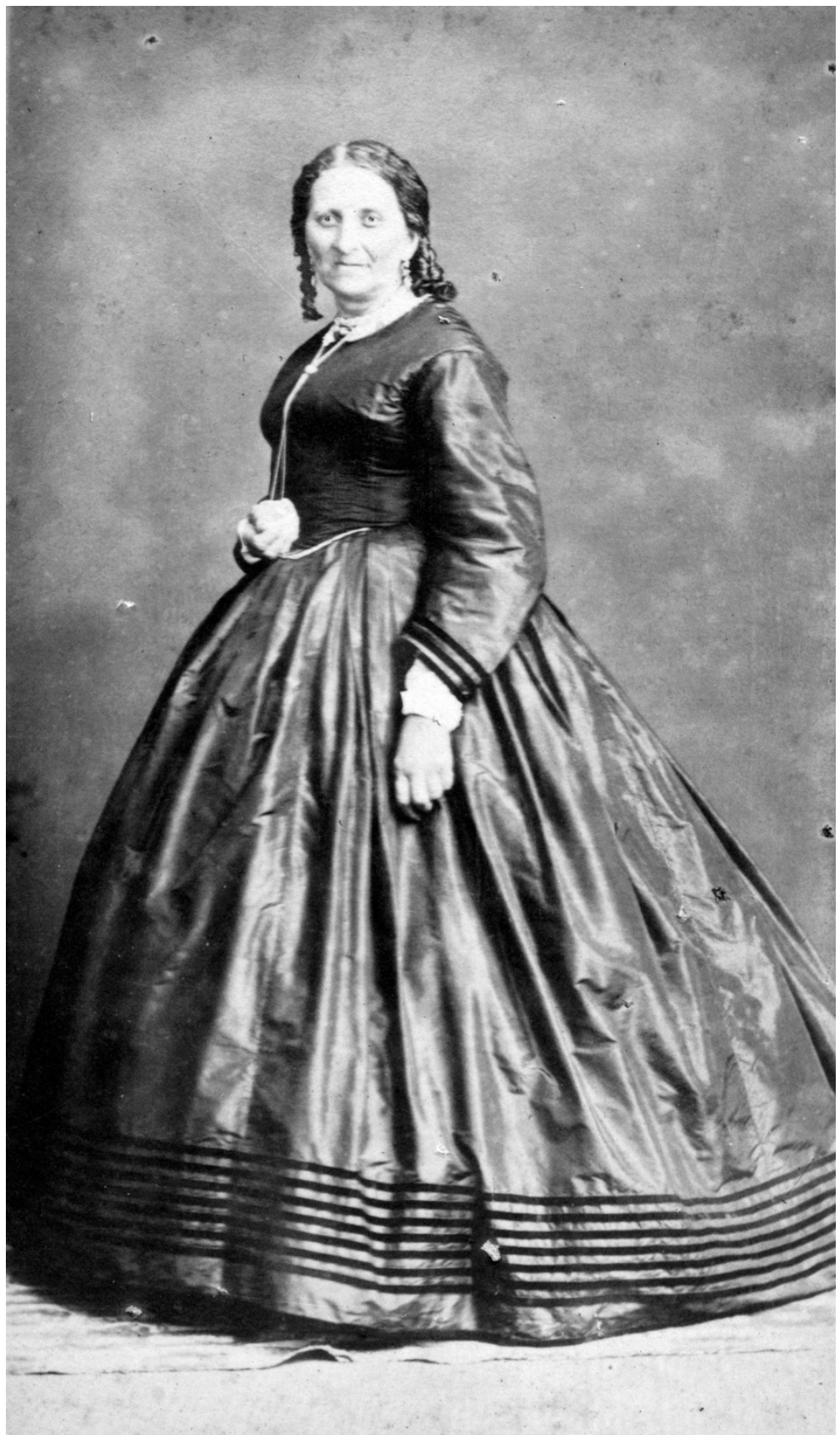

Figura 6. Vestido sobre miriñaque. Fotografía de mujer desconocida. Rafael Belza, hacia 1870. Tenerife. Fuente: Archivo de fotografía histórica de Canarias, Cabildo de Gran Canaria, FEDAC $\left(\mathrm{n}^{\circ}\right.$ registro: 098349). 


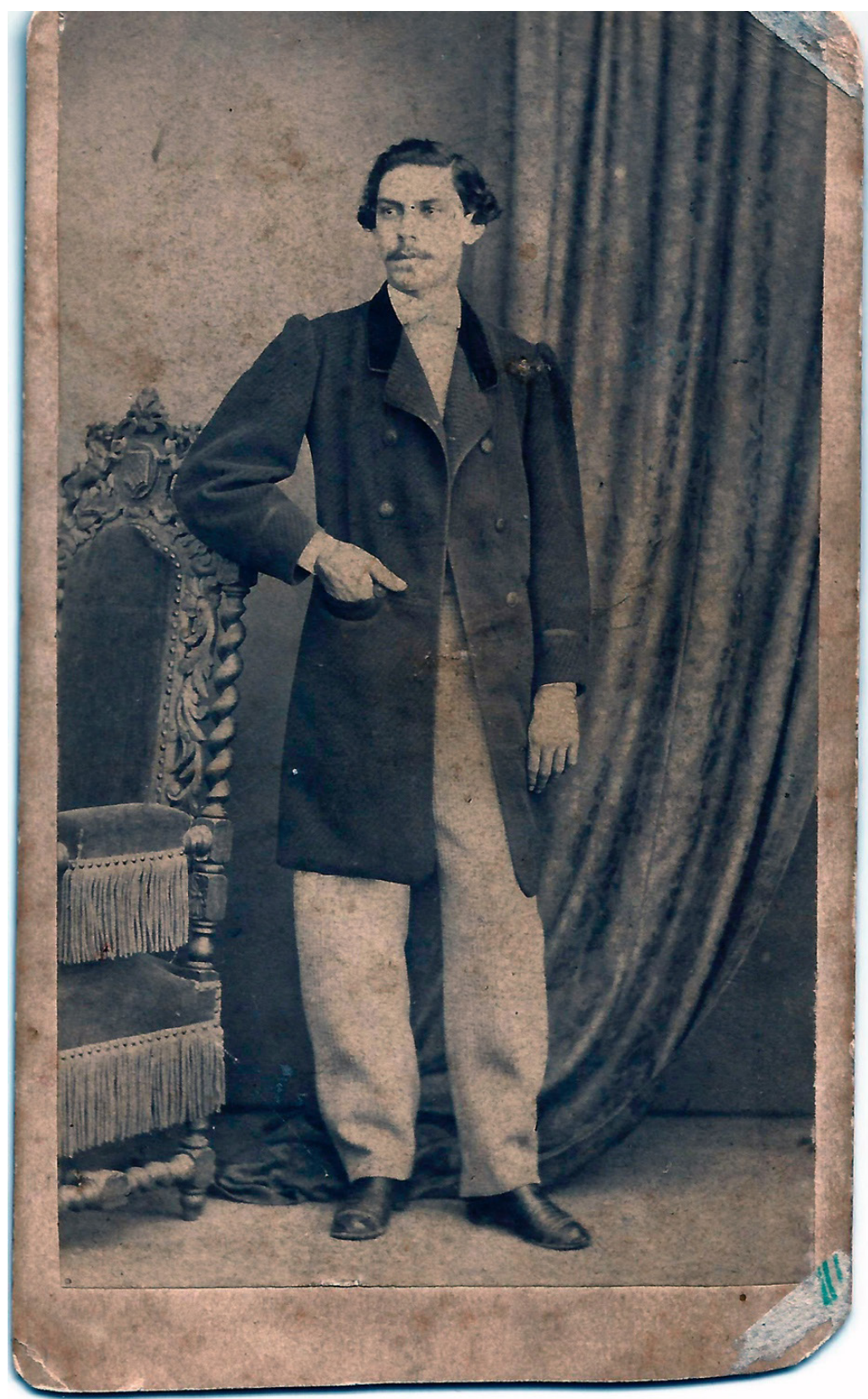

Figura 7. Hombre vestido con paletó. Fotografía de autor desconocido. En el reverso, escrito «Bello» y fechada «1857». Tenerife. Fuente: Colección particular, Santa Cruz de Tenerife. 


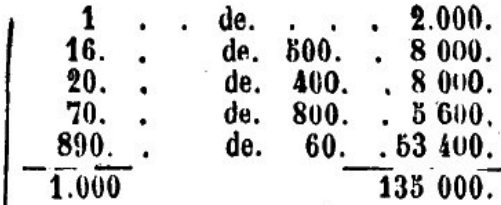

Lns Billc les estarán divilidos en décimos que se espenderán d 12 reales cada uno en la dedmisistracion de Loterias en esta Capilal.

Sanla Cruz de Tenerife 31 de Diciembre de 180̈7. El Admınistrador, Ra fael F. Ruz.

\section{PẾRDIDA}

Se ba perdido en la roche del Domingo $1 .^{\circ}$ del corriente, desde la calle de las lonjas al Tratro una pulsera de oro cou esm raldas, la persuna que la hubiese encoutrado la presentará en esta Redaccion donde será gratificada.

En la calle de la Candelaria almaen num. 15 se ballo do venta vino tinto a real y mediu de plata el cuarti llo.

\section{ALMACEN DE PUERTO FRANCO}

\section{Sastreria francrsa}

\section{Bernard y Labory.}

Gran surtido de ropas hechas y confeccioialas por needidas, paños de sedan y de Elboeuf litas de moila parajanialones, chalecos Y camisas; corbn-

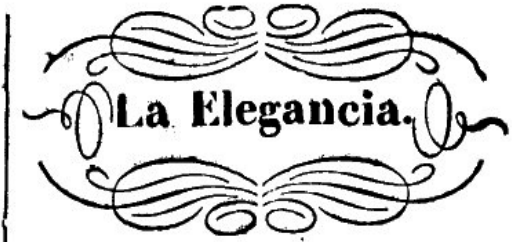

Tn este estab!ecimiento se acaban do recibir sombreros de felpa de última moda y de clase superior, sombreros de Liorna para hombre, de niño y de nitias con adornos y sin ellos, snmbreros de seda para señ̄oras vachurras superfinas, cinlas de tallenas, zapalos dc gona para señoras y niños hasta la edad de 2 años, pulseras de felpa do diferentes colores, cintas de todas elases vestiulos de niños y niñas, juguetes aleũanes, flecos para vestudos, dores, cubiertas de ule para mesas y gallela americana á 11,2 is. plata libra.

-Apvartencia - El jueño de eslo Establecianiento se compromelo a aplanchar los sumbreros de felpa por primera y segunda vez gratis siempro que no esten manchados de grasa.

\section{MASGARAS.}

Las personas que descen adquirir al zun dominó, para usarlos en los bailes y runiones de niáscaras, pueiden ocurrirà la Confiteria lortuguesa accesoria del casíno, donde los hailarán por un alquiler modico.

Figura 8. Anuncio del establecimiento La Elegancia, Santa Cruz de Tenerife. El Eco del Comercio, 16 de enero de 1858. Fuente: Jable. Archivo de Prensa Digital, Biblioteca Universitaria, ULPGC. 


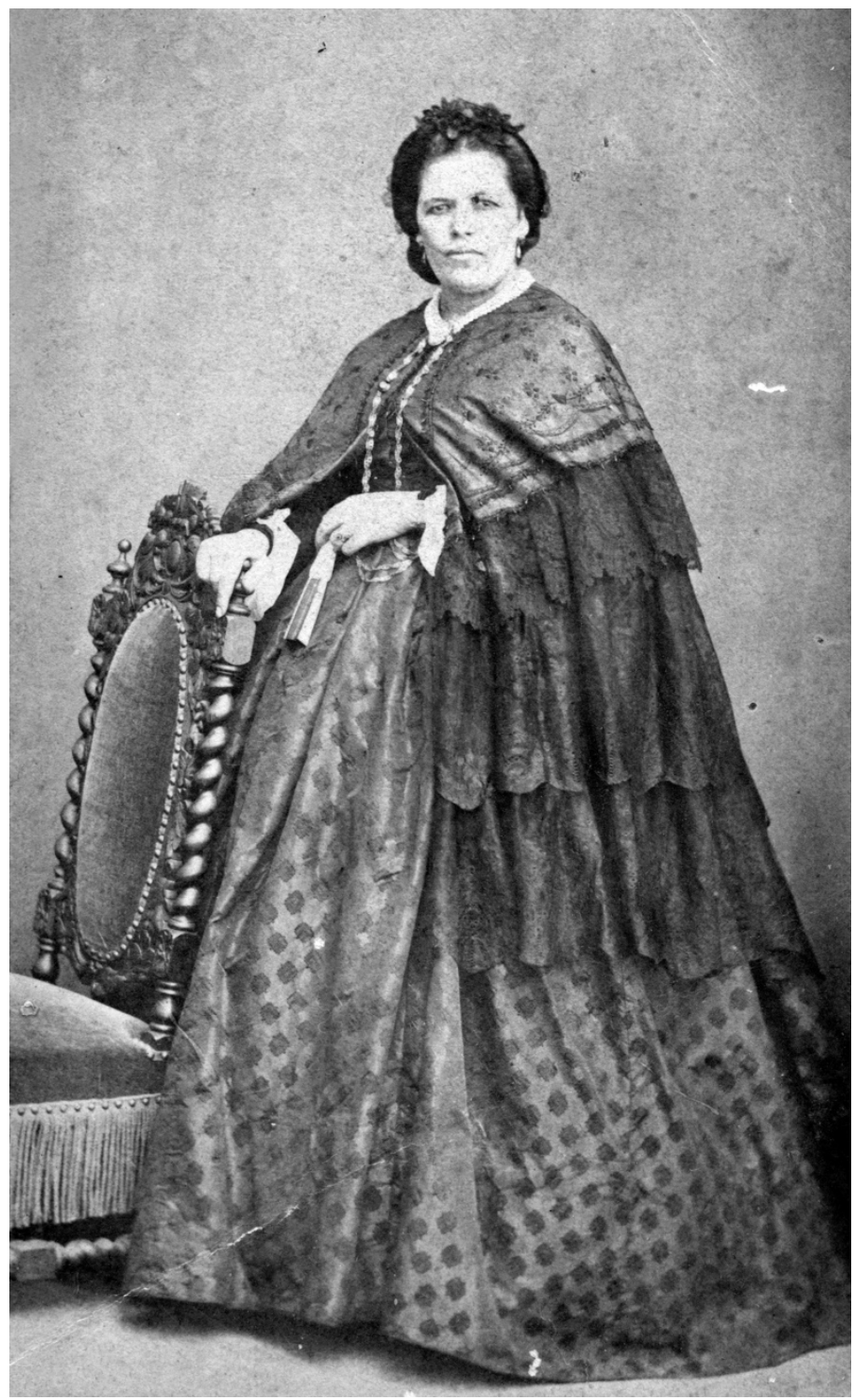

Figura 9. Fotografía de mujer con vestido hilado en canutillo de gros sobre tejido de seda. Rafael Belza, datada en 1890 que adelantamos, en función de la moda, hacia 1870. Tenerife. Fuente: Archivo de fotografía histórica de Canarias, Cabildo de Gran Canaria, FEDAC ( ${ }^{\circ}$ registro: 098356). 


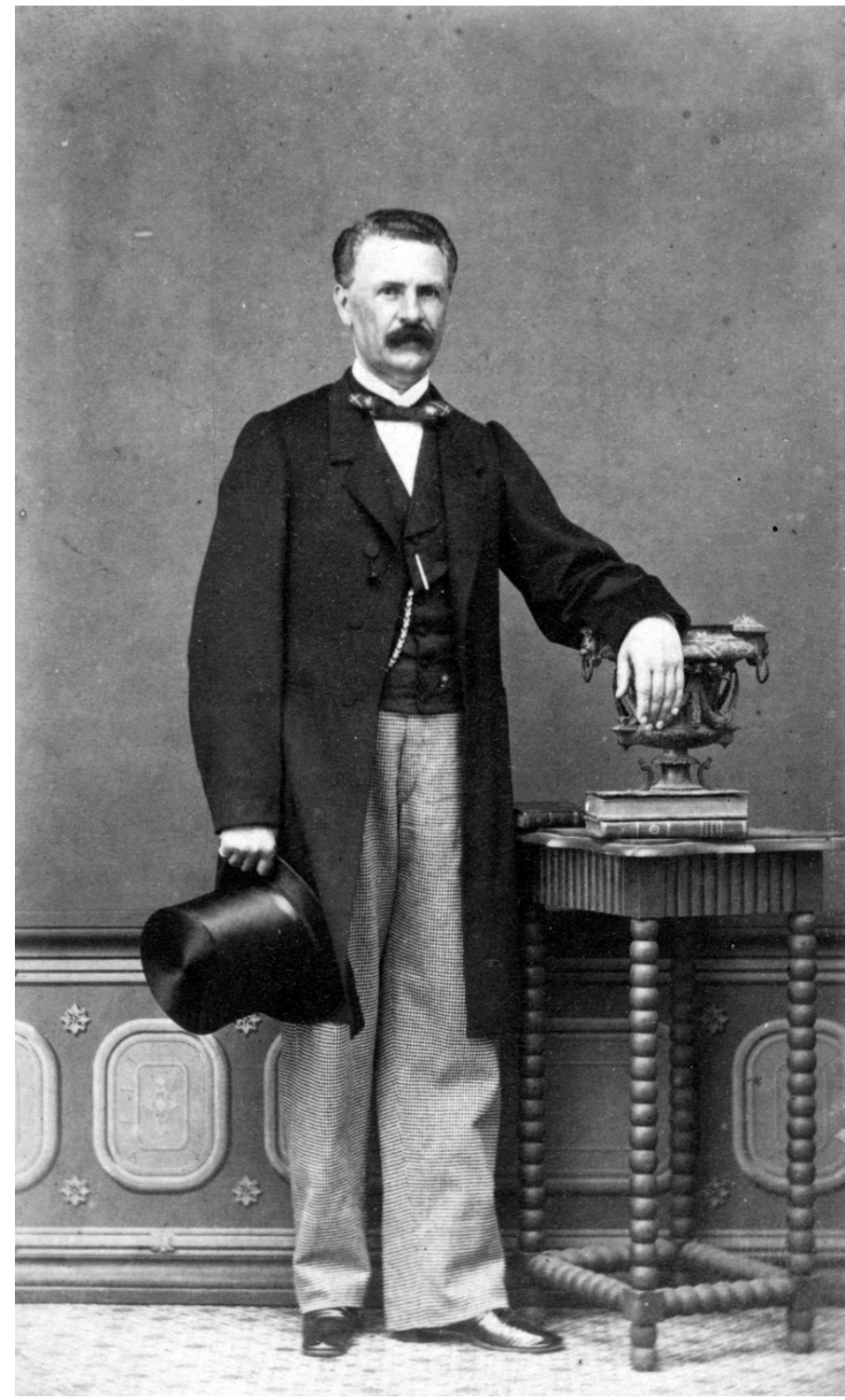

Figura 10. Fotografía de Alejandro Navarro. Indumentaria clásica de día, con chaleco y levita negra, pantalón tartán beige y chistera (top) de fieltro. Santos María Pego. 1865-1870. Tenerife. Fuente: Archivo de fotografía histórica de Canarias, Cabildo de Gran Canaria, FEDAC ( $\mathrm{n}^{\circ}$ registro: 012062). 


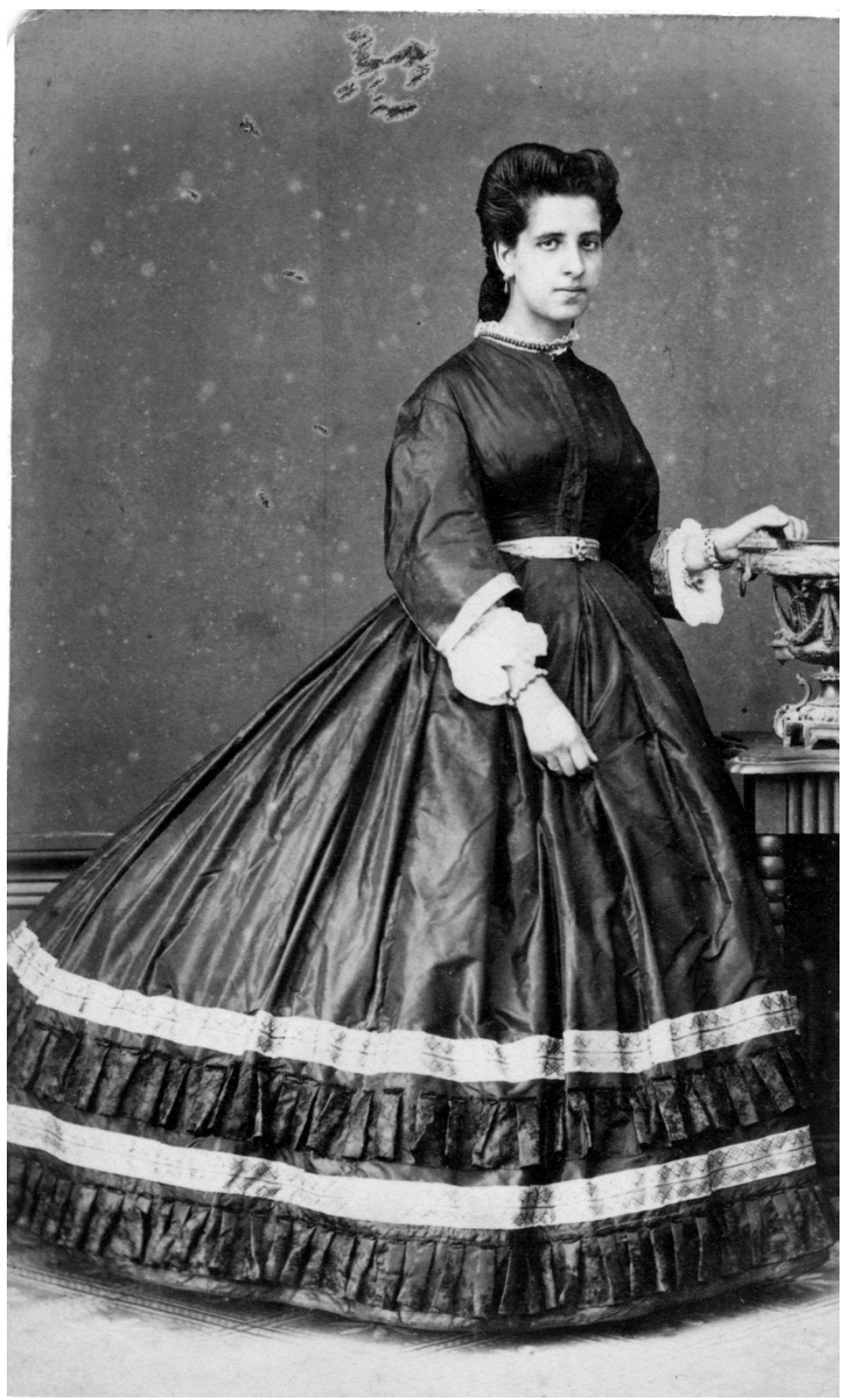

Figura 11. Fotografía de Luisa Cecilia López Echevarrieta. Vestido de paseo en seda negra con encajes y ligera cola sobre miriñaque. Santos María Pego. 1865-1870. Tenerife. Fuente: Archivo de fotografía histórica de Canarias, Cabildo de Gran Canaria, FEDAC ( ${ }^{\circ}$ registro: 012058). 